\title{
Alternative Strategies Toward Sustainable Ammonia Synthesis
}

\author{
Chengcheng $\mathrm{Li}^{1,2,3,4} \cdot$ Tuo Wang ${ }^{1,2,3} \cdot$ Jinlong Gong ${ }^{1,2,3}$
}

Received: 2 January 2020 / Revised: 16 January 2020 / Accepted: 15 February 2020 / Published online: 13 March 2020

(c) The Author(s) 2020

\begin{abstract}
As one of the world's most produced chemicals, ammonia $\left(\mathrm{NH}_{3}\right)$ is synthesized by Haber-Bosch process. This century-old industry nourishes billions of people and promotes social and economic development. In the meantime, 3\%-5\% of the world's natural gas and $1 \%-2 \%$ of the world's energy reserves are consumed, releasing millions of tons of carbon dioxide annually to the atmosphere. The urgency of replacing fossil fuels and mitigating climate change motivates us to progress toward more sustainable methods for $\mathrm{N}_{2}$ reduction reaction based on clean energy. Herein, we overview the emerging advancement for sustainable $\mathrm{N}_{2}$ fixation under mild conditions, which include electrochemical, photo- , plasma-enabled and homogeneous molecular $\mathrm{NH}_{3}$ productions. We focus on $\mathrm{NH}_{3}$ generation by electrocatalysts and photocatalysts. We clarify the features and progress of each kind of $\mathrm{NH}_{3}$ synthesis process and provide promising strategies to further promote sustainable ammonia production and construct state-of-the-art catalytic systems.
\end{abstract}

Keywords Nitrogen fixation $\cdot$ Sustainable ammonia synthesis $\cdot$ Electrocatalyst $\cdot$ Photocatalyst $\cdot$ Ambient conditions

\section{Introduction}

Occupying $78 \%$ of the atmosphere on the earth in volume and being the fifth most abundant element in solar system, nitrogen is essential for the synthesis of nucleic acids and proteins, which are the most important building blocks of life [1]. This condition is based on the reactive nitrogen that entails dinitrogen $\left(\mathrm{N}_{2}\right)$ fixation to its fully hydrogenated product: ammonia $\left(\mathrm{NH}_{3}\right)$. However, $\mathrm{N}_{2}$ fixation is a grand challenge because $\mathrm{N}_{2}$ molecule is thermodynamically stable with an extremely high triple-bond energy $(941 \mathrm{~kJ} / \mathrm{mol})$ and insurmountable first-bond cleavage energy $(410 \mathrm{~kJ} / \mathrm{mol})$ [2]. In nature, only a small group of microorganisms could biologically fix $\mathrm{N}_{2}$ to $\mathrm{NH}_{3}$ with the enzyme nitrogenase [3-5]. The most common molybdenum (Mo)-based nitrogenase is a

Tuo Wang

wangtuo@tju.edu.cn

1 School of Chemical Engineering and Technology, Tianjin University, Tianjin 300072, China

2 Key Laboratory for Green Chemical Technology of Ministry of Education, Tianjin 300072, China

3 Collaborative Innovation Center of Chemical Science and Engineering, Tianjin 300072, China

4 School of Materials Sciences and Engineering, Nanyang Technological University, Singapore 639798, Singapore two-component system, with Fe protein as electron-transfer media and FeMo protein as the $\mathrm{N}_{2}$-binding and reduction site (Fig. 1a) [6, 7]. During reaction, electrons flow from a pair of adenosine triphosphate (ATP) molecules to the Fe-S cluster within the Fe protein, pass through the $\mathrm{P}$ cluster on FeMo protein and finally arrive at the FeMo cofactor (FeMoco), where the reduction of $\mathrm{N}_{2}$ to $\mathrm{NH}_{3}$ occurs. The accumulation of $8 \mathrm{e}^{-}$results in the reduction of one $\mathrm{N}_{2}$ molecule along with the reductive elimination of one $\mathrm{H}_{2}$ molecule $[8,9]$ :

$\mathrm{N}_{2}+8 \mathrm{H}^{+}+8 \mathrm{e}^{-}+16 \mathrm{MgATP} \rightarrow 2 \mathrm{NH}_{3}+\mathrm{H}_{2}+16 \mathrm{MgADP}+16 \mathrm{P}_{\mathrm{i}}$

Figure $1 \mathrm{~b}$ illustrates the structure of FeMoco, which contains seven $\mathrm{Fe}$ atoms and one Mo atom that are bonded to the sulfur bridge with an interstitial carbon atom [10].

Although nitrogenase has long existed in nature, artificial $\mathrm{N}_{2}$ fixation was invented not until the early twentieth century by Fritz Haber, and Carl Bosch developed the necessary engineering skills [11]. This pioneering work, known as the Haber-Bosch (H-B) process, successfully converts atmospheric $\mathrm{N}_{2}$ to $\mathrm{NH}_{3}$ on a large scale by reacting with $\mathrm{H}_{2}$ using an iron metal-based catalyst under high temperature $\left(400-500{ }^{\circ} \mathrm{C}\right)$ and pressure (100-200 bar):

$\mathrm{N}_{2}+3 \mathrm{H}_{2} \rightarrow 2 \mathrm{NH}_{3} \quad \Delta_{\mathrm{r}} H_{0}=-91.8 \mathrm{~kJ} / \mathrm{mol}$ 


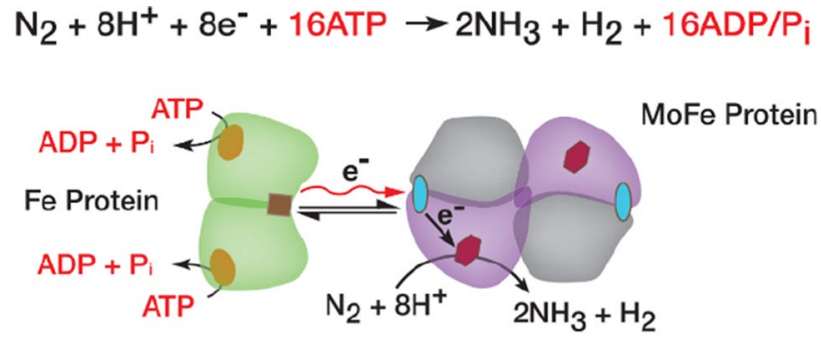

(a)

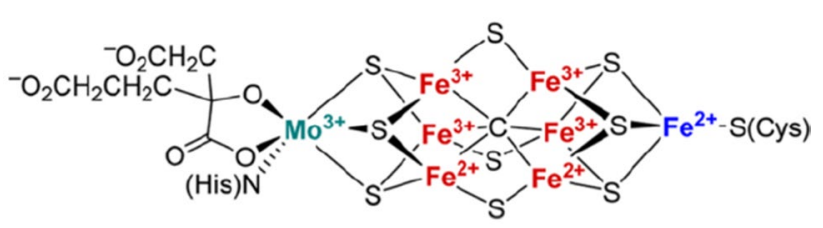

(b)

Fig. 1 Biological $\mathrm{N}_{2}$ fixation. a Reaction pathway of $\mathrm{N}_{2}$ reduction to $\mathrm{NH}_{3}$ on nitrogenase. Reproduced with permission from Ref. [7]. Copyright 2016, AAAS. b Structure of the resting-state FeMoco. Reproduced with permission from Ref. [10]. Copyright 2016, American Chemical Society

To date, the worldwide output of $\mathrm{NH}_{3}$ by $\mathrm{H}-\mathrm{B}$ process has exceeded 200 million metric tons per year, which contributes to half of the global nitrogen fixation [12]. A total of $80 \%$ of the produced $\mathrm{NH}_{3}$ is used for fertilizer production [13], whereas the remaining reserves are used in refrigeration, explosives, pharmaceuticals, plastics and other industrial processes [14]. $\mathrm{NH}_{3}$ is a promising chemical energy carrier candidate, and it could be converted into hydrogen at point of use, showing great application potential in fuel cell technology $[15,16]$. Nitrogen fertilizer has supported nearly 4 billion people born since 1908 [17], and more than half of the nitrogen found in the modern human bodies originates from the $\mathrm{H}-\mathrm{B}$ process [18]. Nonetheless, $\mathrm{H}-\mathrm{B}$ process consumes $3 \%-5 \%$ of the world's natural gas for $\mathrm{H}_{2}$ extraction and $1 \%-2 \%$ of the world's energy reserves, belching out millions of tons of carbon dioxide $\left(\mathrm{CO}_{2}\right)$, which accounts for $1.5 \%$ of all greenhouse gas emissions, annually to the atmosphere $[19,20]$. Over the past 150 years, atmospheric $\mathrm{CO}_{2}$ concentration has increased from $280 \times 10^{-6}$ to $408 \times 10^{-6}$ as a result of intensive fossil fuel consumption [21]. The urgency of limiting global warming and fossil energy use has led to intense research on $\mathrm{N}_{2}$ reduction driven by renewable sources, thus providing effective strategies to close the gap in carbon cycle and address the food supply in the future [22]. On the other hand, $\mathrm{H}-\mathrm{B}$ process is a highly centralized industry, but fertilizer consumption is distributed throughout agricultural territories [23]. This condition results in elevated transportation costs and emissions, especially for remote and underdeveloped regions.
Therefore, sustainable strategies that would allow $\mathrm{NH}_{3}$ production under benign conditions at distributed sources must be developed [22].

In addition to enzymatic $\mathrm{N}_{2}$ fixation in nature, several alternative methods for $\mathrm{N}_{2}$ reduction reaction (NRR), including electrocatalysis [13, 24-30], photocatalysis [19, 23, 29, 31-33], plasma catalysis [14, 34] and homogeneous molecular catalysis, have been developed [2, 35]. Compared with the $\mathrm{H}-\mathrm{B}$ process that requires high temperature and pressure, the reactions of these alternative methods are induced under mild conditions, which include partially reduced temperature/pressure [36], high or intermediate temperature with atmospheric pressure [37, 38] and room temperature (RT) with atmospheric pressure (ambient conditions) [39]. On the other hand, the hydrogen of synthesized $\mathrm{NH}_{3}$ in these alternative methods originates from $\mathrm{H}_{2}$ (same as in $\mathrm{H}-\mathrm{B}$ process) or $\mathrm{H}_{2} \mathrm{O}$ molecules. From a thermodynamic point of view [22], $\mathrm{NH}_{3}$ synthesis using $\mathrm{N}_{2}$ and $\mathrm{H}_{2} \mathrm{O}$ at ambient conditions is extremely challenging, but such process will result in profound influence on the sustainable future once achieved.

\section{Electrochemical Ammonia Synthesis}

Motivated by the urgent targets of $\mathrm{CO}_{2}$ emission reduction and decreasing costs of renewable energy such as solar and wind, the electrical grid is rapidly transforming toward a low-carbon system. The necessity of protons/electrons for the completion of natural enzymatic $\mathrm{N}_{2}$ fixation (reaction 1) indicates that $\mathrm{NH}_{3}$ could be synthesized via an electrochemical process. Investigating electrochemical $\mathrm{N}_{2}$ reduction could not only realize distributed $\mathrm{NH}_{3}$ production but also balance the supply in electrical grids due to the intermittency of renewable sources. Thus far, several kinds of electrolytes $[13,26]$ are used for electrochemical $\mathrm{NH}_{3}$ synthesis: (1) solid electrolytes, such as solid polymer or perovskites, which are operated from RT to high temperature $\left(T>500{ }^{\circ} \mathrm{C}\right)$; (2) molten electrolytes which are operated at intermediate temperature (100 ${ }^{\circ} \mathrm{C}<T<500{ }^{\circ} \mathrm{C}$ ); (3) liquid electrolytes which are operated at near RT. In the first decade of this millennium, research was focused on $\mathrm{NH}_{3}$ synthesis in solid electrolytes or molten salts, and relatively high $\mathrm{NH}_{3}$ production rate up to the order of $10^{-8} \mathrm{~mol} /\left(\mathrm{cm}^{2} \mathrm{~s}\right)$ has been achieved at elevated temperature [13]; however, these methods remain inapplicable for practical use. Research on $\mathrm{N}_{2}$ fixation at ambient conditions in liquid electrolytes, especially aqueous media, has experienced an explosive growth in the last 4 or 5 years [40], aiming at harvesting $\mathrm{NH}_{3}$ from ubiquitous nitrogen and water by renewable electricity. 


\section{Solid-State Electrochemical Ammonia Synthesis (SSAS)}

The reaction kinetics of $\mathrm{NH}_{3}$ synthesis is favored at high temperatures. However, general electrolytes could not be operated in the high-temperature region. Highly protonconductive solid-state materials working at high temperatures were discovered in 1980s [41]. In 1998, Marnellos and Stoukides [37] first demonstrated the electrochemical synthesis of $\mathrm{NH}_{3}$ from $\mathrm{N}_{2}$ and $\mathrm{H}_{2}$ using a solid proton conductor. Typically, the SSAS system is composed of two porous electrodes (anode and cathode) separated by a dense solid electrolyte, which blocks gas diffusion and facilitates ion transport of protons or oxide anions [42] (Fig. 2).

\section{Proton-Conducting SSAS}

In Marnellos's work [37], the electrolyte was a solid proton conductor composed of strontia-ceria-ytterbia (SCY) perovskite in the form of $\mathrm{SrCe}_{0.95} \mathrm{Yb}_{0.05} \mathrm{O}_{3}$, whereas two porous polycrystalline palladium electrodes were deposited on the two sides of the SCY electrolyte as anode and cathode (Fig. 2a). $\mathrm{NH}_{3}$ was successfully generated from $\mathrm{N}_{2}$ and $\mathrm{H}_{2}$ [Eqs. (3), (4)]:

$3 \mathrm{H}_{2} \rightarrow 6 \mathrm{H}^{+}+6 \mathrm{e}^{-}$(anode)

$\mathrm{N}_{2}+6 \mathrm{H}^{+}+6 \mathrm{e}^{-} \rightarrow 2 \mathrm{NH}_{3}$ (cathode)

At $570{ }^{\circ} \mathrm{C}$ and atmospheric pressure, a current efficiency of $78 \%$ was observed, leading to $\mathrm{NH}_{3}$ production rate of $4.5 \times 10^{-9} \mathrm{~mol} /\left(\mathrm{cm}^{2} \mathrm{~s}\right)$. Hereafter, dozens of proton-conducting electrolyte materials were tested, including perovskite-type oxides [43, 44], pyrochlore-type oxides [45, 46], fluorite-type oxides [47], polymers [48-50] and composite electrolytes [51, 52].
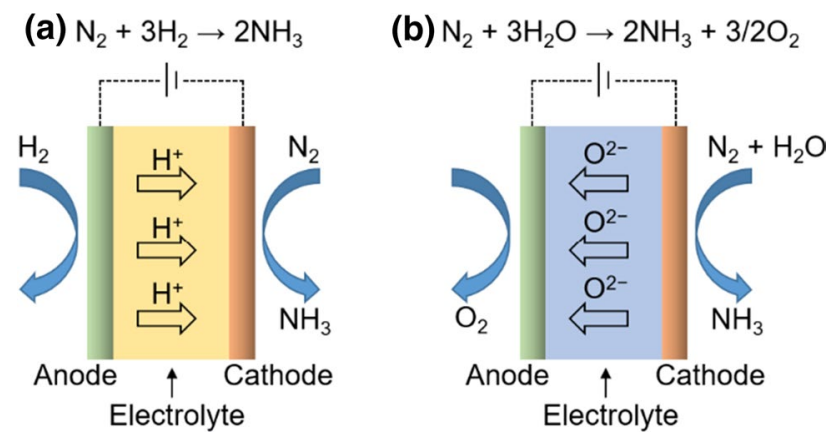

Fig. 2 Schematic of SSAS systems using a solid-state proton-conducting electrolyte and b solid-state oxygen anion-conducting electrolyte. Inert carrier gas is omitted. Adapted with permission from Ref. [42]. Copyright 2014, Frontiers Production Office
Liu and coworkers [44] synthesized perovskite-type oxides $\mathrm{BaCe}_{0.90} \mathrm{Sm}_{0.10} \mathrm{O}_{3-\delta}$ and $\mathrm{BaCe}_{0.80} \mathrm{Gd}_{0.10} \mathrm{Sm}_{0.10} \mathrm{O}_{3-\delta}$ by sol-gel method. Both materials showed high proton conductivity for SSAS, leading to a maximum $\mathrm{NH}_{3}$ production rate of $5.82 \times 10^{-9} \mathrm{~mol} /\left(\mathrm{cm}^{2} \mathrm{~s}\right)$ at $620^{\circ} \mathrm{C}$. Chen and Ma [53] fabricated perovskite-type $\mathrm{BaCe}_{1-x} \mathrm{Gd}_{x} \mathrm{O}_{3-\alpha}(0.05 \leq x \leq 0.20)$ ceramic by microemulsion method and sintering. This ceramic exhibited proton-conducting properties from 300 to $600{ }^{\circ} \mathrm{C}$ in hydrogen atmosphere. When $90 \mu \mathrm{m}$ thick $\mathrm{BaCe}_{0.85} \mathrm{Gd}_{0.15} \mathrm{O}_{3-\alpha}$ film was used as the electrolyte, a $\mathrm{NH}_{3}$ formation rate of $4.63 \times 10^{-9} \mathrm{~mol} /\left(\mathrm{cm}^{2} \mathrm{~s}\right)$ was obtained.

$\mathrm{Xie}$ et al. [45] prepared pyrochlore-type oxides of $\mathrm{La}_{1.9} \mathrm{Ca}_{0.1} \mathrm{Zr}_{2} \mathrm{O}_{6.95}$ via sol-gel method as proton-conducting electrolyte for SSAS. The rate of $\mathrm{NH}_{3}$ evolution was up to $2.0 \times 10^{-9} \mathrm{~mol} /\left(\mathrm{cm}^{2} \mathrm{~s}\right)$ at $520{ }^{\circ} \mathrm{C}$. When $\mathrm{Zr}$ was replaced by $\mathrm{Ce}$, a rate of $1.3 \times 10^{-9} \mathrm{~mol} /\left(\mathrm{cm}^{2} \mathrm{~s}\right)$ was observed [46]. The same group also studied proton conduction properties of fluorite-type oxide ceramics $\mathrm{Ce}_{0.8} \mathrm{M}_{0.2} \mathrm{O}_{2-\delta}(\mathrm{M}=\mathrm{La}, \mathrm{Y}, \mathrm{Gd}$, $\mathrm{Sm})$ from 400 to $800{ }^{\circ} \mathrm{C}$ [47]. At $650{ }^{\circ} \mathrm{C}$, the rate of $\mathrm{NH}_{3}$ evolution varied from $7.2 \mathrm{~mol} /\left(\mathrm{cm}^{2}\right.$ s) to $8.2 \times 10^{-9} \mathrm{~mol} /$ $\left(\mathrm{cm}^{2} \mathrm{~s}\right)$ depending on various $\mathrm{M}$ elements.

The aforementioned perovskite, pyrochlore and fluoritetype electrolytes belong to high-temperature proton conductors for $\mathrm{NH}_{3}$ synthesis at atmospheric pressure. Nonetheless, high temperature would increase energy consumption and cause $\mathrm{NH}_{3}$ decomposition. Solid polymers, such as Nafion, are good proton conductors that can be used as electrolytes for SSAS at atmospheric pressure and low temperature. Kyriacou and coworkers [54] first introduced Nafion membrane to SSAS with Pt and Ru, which were used as anode and cathode, respectively. At $-1.02 \mathrm{~V}$ and $90{ }^{\circ} \mathrm{C}$, this system achieved an ammonia formation rate of $2.12 \times 10^{-11} \mathrm{~mol} /$ $\left(\mathrm{cm}^{2} \mathrm{~s}\right)$ with a current efficiency of $0.24 \%$. The performance of Nafion-based SSAS was greatly improved when metal electrodes were replaced by composite oxides. Liu's group [48] adopted fluorite-type $\mathrm{Ce}_{0.8} \mathrm{Sm}_{0.2} \mathrm{O}_{2-\delta}$ and perovskitetype $\mathrm{SmFe}_{0.7} \mathrm{Cu}_{0.3-x} \mathrm{Ni}_{x} \mathrm{O}_{3}$ as the anode and cathode, respectively, in a Nafion-based SSAS cell. At $-2 \mathrm{~V}$ and $80^{\circ} \mathrm{C}$, this system yielded $\mathrm{NH}_{3}$ with a fast rate of $1.13 \times 10^{-8} \mathrm{~mol} /$ $\left(\mathrm{cm}^{2} \mathrm{~s}\right)$ and a high current efficiency of $90.4 \%$. This rate is the highest among SSAS cells to date.

\section{$\mathrm{O}^{2-}$-Conducting SSAS}

In addition to proton-conducting electrolytes, $\mathrm{O}^{2-}$-conducting solid electrolyte cells could realize $\mathrm{NH}_{3}$ production from $\mathrm{N}_{2}$ and $\mathrm{H}_{2} \mathrm{O}$ (Fig. 2b):

$3 \mathrm{O}^{2-} \rightarrow 3 / 2 \mathrm{O}_{2}+6 \mathrm{e}^{-}$(anode)

$\mathrm{N}_{2}+3 \mathrm{H}_{2} \mathrm{O}+6 \mathrm{e}^{-} \rightarrow 2 \mathrm{NH}_{3}+3 \mathrm{O}^{2-}$ (cathode) 
$\mathrm{N}_{2}+3 \mathrm{H}_{2} \mathrm{O} \rightarrow 2 \mathrm{NH}_{3}+3 / 2 \mathrm{O}_{2}$ (overall) $\quad \Delta_{\mathrm{r}} H_{0}=765.6 \mathrm{~kJ} / \mathrm{mol}$

Stoukides's group [55] reported yttria-stabilized zirconia $\left(8 \% \mathrm{Y}_{2} \mathrm{O}_{3} / \mathrm{ZrO}_{2}\right)$ as $\mathrm{O}^{2-}$-conducting electrolyte for SSAS using $\mathrm{N}_{2}$ and $\mathrm{H}_{2} \mathrm{O}$ as feed gases. At $650{ }^{\circ} \mathrm{C}$ and atmospheric pressure, an ammonia rate of $1.50 \times 10^{-13} \mathrm{~mol} /\left(\mathrm{cm}^{2} \mathrm{~s}\right)$ was obtained. Amar et al. [56] presented ammonia synthesis from wet nitrogen (with $\mathrm{H}_{2} \mathrm{O}$ ) at $375-425{ }^{\circ} \mathrm{C}$ in an $\mathrm{O}^{2-}$-conducting composite electrolyte: $\mathrm{Ce}_{0.8} \mathrm{Gd}_{0.18} \mathrm{Ca}_{0.02} \mathrm{O}_{2-\delta}-(\mathrm{Li} / \mathrm{Na} / \mathrm{K})_{2} \mathrm{CO}_{3}$. A maximum ammonia formation rate of $4.0 \times 10^{-10} \mathrm{~mol} /\left(\mathrm{cm}^{2} \mathrm{~s}\right)$ with a current efficiency of $3.87 \%$ was observed at $375^{\circ} \mathrm{C}$ and $1.4 \mathrm{~V}$ on a $\mathrm{La}_{0.75} \mathrm{Sr}_{0.25} \mathrm{Cr}_{0.5} \mathrm{Fe}_{0.5} \mathrm{O}_{3-\delta}-\mathrm{Ce}_{0.8} \mathrm{Gd}_{0.18} \mathrm{Ca}_{0.02} \mathrm{O}_{2-\delta}$ composite cathode.

\section{Pros and Cons of SSAS}

$\mathrm{NH}_{3}$ synthesis in solid-state electrolytes is usually conducted at elevated temperatures, because of not only hastened reaction kinetics but also substantially boosted conductivity of electrolytes. An appreciable production rate of up to $10^{-8} \mathrm{~mol} /\left(\mathrm{cm}^{2} \mathrm{~s}\right)$ can be achieved from $\mathrm{N}_{2}$ and $\mathrm{H}_{2}$ [Eq. (2)], but this exothermic reaction is not thermodynamically favorable at high temperatures, necessitating a trade-off for maximizing $\mathrm{NH}_{3}$ yield. $\mathrm{H}_{2}$ production from natural gas reforming is energy intensive and causes most of $\mathrm{CO}_{2}$ release. Although $\mathrm{NH}_{3}$ production from $\mathrm{N}_{2}$ and $\mathrm{H}_{2} \mathrm{O}$ [Eq. (7)] is endothermic and theoretically carbon-free, the weak reducing power and low conductivity of $\mathrm{O}^{2-}$ greatly restrict $\mathrm{NH}_{3}$ yield.

\section{Electrochemical Ammonia Synthesis in Molten Electrolytes}

Compared with SSAS, molten electrolytes enhance the ionic conductivity and reduce the operating temperature of the reactions. In molten alkali metal salts, $\mathrm{N}^{3-}$ is stabilized and acts as intermediate product from $\mathrm{N}_{2}$ to $\mathrm{NH}_{3}$. Moreover, protic solvents are avoided, which eliminates the competitive hydrogen evolution reaction (HER).

Ito and coworkers $[57,58]$ discovered that $\mathrm{N}_{2}$ gas could be electrochemically reduced to $\mathrm{N}^{3-}$ in molten $\mathrm{LiCl}-\mathrm{KCl}-\mathrm{Li}_{3} \mathrm{~N}$ eutectic melts. Afterward, they used the molten salt system for electrochemical $\mathrm{NH}_{3}$ synthesis (Fig. 3a) [59]. $\mathrm{N}^{3-}$ is the conducting ion in molten $\mathrm{LiCl}-\mathrm{KCl}-\mathrm{Li}_{3} \mathrm{~N}$ or $\mathrm{LiCl}-\mathrm{KCl}-\mathrm{CsCl}-\mathrm{Li}_{3} \mathrm{~N}$ electrolytes. The reactions on the two electrodes are as follows:

$\mathrm{N}_{2}+6 \mathrm{e}^{-} \rightarrow 2 \mathrm{~N}^{3-}$ (cathode)

$2 \mathrm{~N}^{3-}+3 \mathrm{H}_{2} \rightarrow 2 \mathrm{NH}_{3}+6 \mathrm{e}^{-}$(anode)

In this system, the $\mathrm{NH}_{3}$ synthesis rate was correlated to hydrogen partial pressure in the gas electrode instead of electrolysis potential [60]. The rate-determining step was proposed to be the dissolution/diffusion of hydrogen in the molten electrolytes. The highest $\mathrm{NH}_{3}$ production rate was $3.33 \times 10^{-8} \mathrm{~mol} /\left(\mathrm{cm}^{2} \mathrm{~s}\right)$ with a current efficiency of $72 \%$ at $400{ }^{\circ} \mathrm{C}$ [60]. In the presence of $\mathrm{N}^{3-}$, however, a portion of $\mathrm{NH}_{3}$ could dissolve to form imide $\left(\mathrm{NH}^{2-}\right)$ and amide $\left(\mathrm{NH}_{2}{ }^{-}\right)$anions, which might lower the $\mathrm{NH}_{3}$ production rate [61]. Apart from $\mathrm{H}_{2}$, other hydrogen sources, such as $\mathrm{H}_{2} \mathrm{O}$ [62, 63], $\mathrm{HCl}$ [64], $\mathrm{H}_{2} \mathrm{~S}$ [65] and $\mathrm{CH}_{4}$ [66], were explored for electrochemical $\mathrm{NH}_{3}$ synthesis in $\mathrm{LiCl}-\mathrm{KCl}-\mathrm{CsCl}$ eutectic melts.

Licht and colleagues [36] illustrated a configuration for electrochemical $\mathrm{NH}_{3}$ synthesis, where $\mathrm{NH}_{3}$ was generated by electrolysis of air and water steam in molten 0.5 $\mathrm{NaOH} / 0.5 \mathrm{KOH}$ in the presence of nano- $\mathrm{Fe}_{2} \mathrm{O}_{3}$ catalysts. At $200{ }^{\circ} \mathrm{C}$ and $1.2 \mathrm{~V}, \mathrm{NH}_{3}$ was produced under $2 \mathrm{~mA} / \mathrm{cm}^{2}$ of applied current with a current efficiency of $35 \%$. At the largest current density of $200 \mathrm{~mA} / \mathrm{cm}^{2}$, the production rate of $\mathrm{NH}_{3}$ was as high as $1.0 \times 10^{-8} \mathrm{~mol} /\left(\mathrm{cm}^{2} \mathrm{~s}\right)$. The high surface area of the nano- $\mathrm{Fe}_{2} \mathrm{O}_{3}$ that remained colloidal in electrolysis was critical to the $\mathrm{NH}_{3}$ synthesis process, whereas macro- $\mathrm{Fe}_{2} \mathrm{O}_{3}$ descended and accumulated at the cell bottom without discernible $\mathrm{NH}_{3}$ production. Notably, solar thermal energy could be introduced into the system, resulting in a solar thermal electrochemical process (Fig. 3b) [67].

McEnaney et al. [68] reported an ammonia synthesis system from $\mathrm{N}_{2}$ and $\mathrm{H}_{2} \mathrm{O}$ using a lithium cycling electrification strategy at atmospheric pressure (Fig. 3c). This lithium-mediated cycling process combines three steps:

Step 1: Electrolyzing molten $\mathrm{LiOH}$ to metallic $\mathrm{Li}$ at $400{ }^{\circ} \mathrm{C}-450{ }^{\circ} \mathrm{C}$ :

$$
6 \mathrm{LiOH} \rightarrow 6 \mathrm{Li}+3 \mathrm{H}_{2} \mathrm{O}+3 / 2 \mathrm{O}_{2(\mathrm{~g})}
$$

Step 2: Nitridation of metallic Li to form $\mathrm{Li}_{3} \mathrm{~N}$ :

$$
6 \mathrm{Li}+\mathrm{N}_{2(\mathrm{~g})} \rightarrow 2 \mathrm{Li}_{3} \mathrm{~N}_{(\mathrm{s})}
$$

Step 3: $\mathrm{Li}_{3} \mathrm{~N}$ hydrolysis to release $\mathrm{NH}_{3}$ and regenerate LiOH:

$$
2 \mathrm{Li}_{3} \mathrm{~N}_{(\mathrm{s})}+6 \mathrm{H}_{2} \mathrm{O} \rightarrow 6 \mathrm{LiOH}+2 \mathrm{NH}_{3}
$$

This stepwise approach circumvents direct $\mathrm{N}_{2}$ protonation and therefore substantially inhibits undesired HER, leading to a high initial current efficiency of $88.5 \%$. The ease of dissociation of the strong $\mathrm{N}-\mathrm{N}$ bond over metallic $\mathrm{Li}$ and diffusion processes to form $\mathrm{Li}_{3} \mathrm{~N}$ at $\mathrm{RT}$ are keys to the demonstrated cycle. This strategy could be coupled with renewable sources of electricity to facilitate localized sustainable $\mathrm{NH}_{3}$ synthesis. 
Fig. 3 Electrochemical $\mathrm{NH}_{3}$ synthesis in molten electrolytes. a Schematic of the principle of electrolytic synthesis of $\mathrm{NH}_{3}$ from $\mathrm{N}_{2}$ and $\mathrm{H}_{2}$ in molten $\mathrm{LiCl}-\mathrm{KCl}-\mathrm{CsCl}$ salts containing $\mathrm{N}^{3-}$. Adapted with permission from Ref. [59]. Copyright 2003, American Chemical Society. b Illustration of electrochemical $\mathrm{NH}_{3}$ synthesis by electrolysis of air and water steam in a molten hydroxide suspension of nano$\mathrm{Fe}_{2} \mathrm{O}_{3}$ catalysts. Reproduced with permission from Ref. [67]. Copyright 2014, American Chemical Society. c Schematic of a stepwise lithium-mediated cycling process for the sustainable $\mathrm{NH}_{3}$ production from $\mathrm{N}_{2}$ and $\mathrm{H}_{2} \mathrm{O}$ driven by renewable energy sources. Reproduced with permission from Ref. [68]. Copyright 2017, The Royal Society of Chemistry
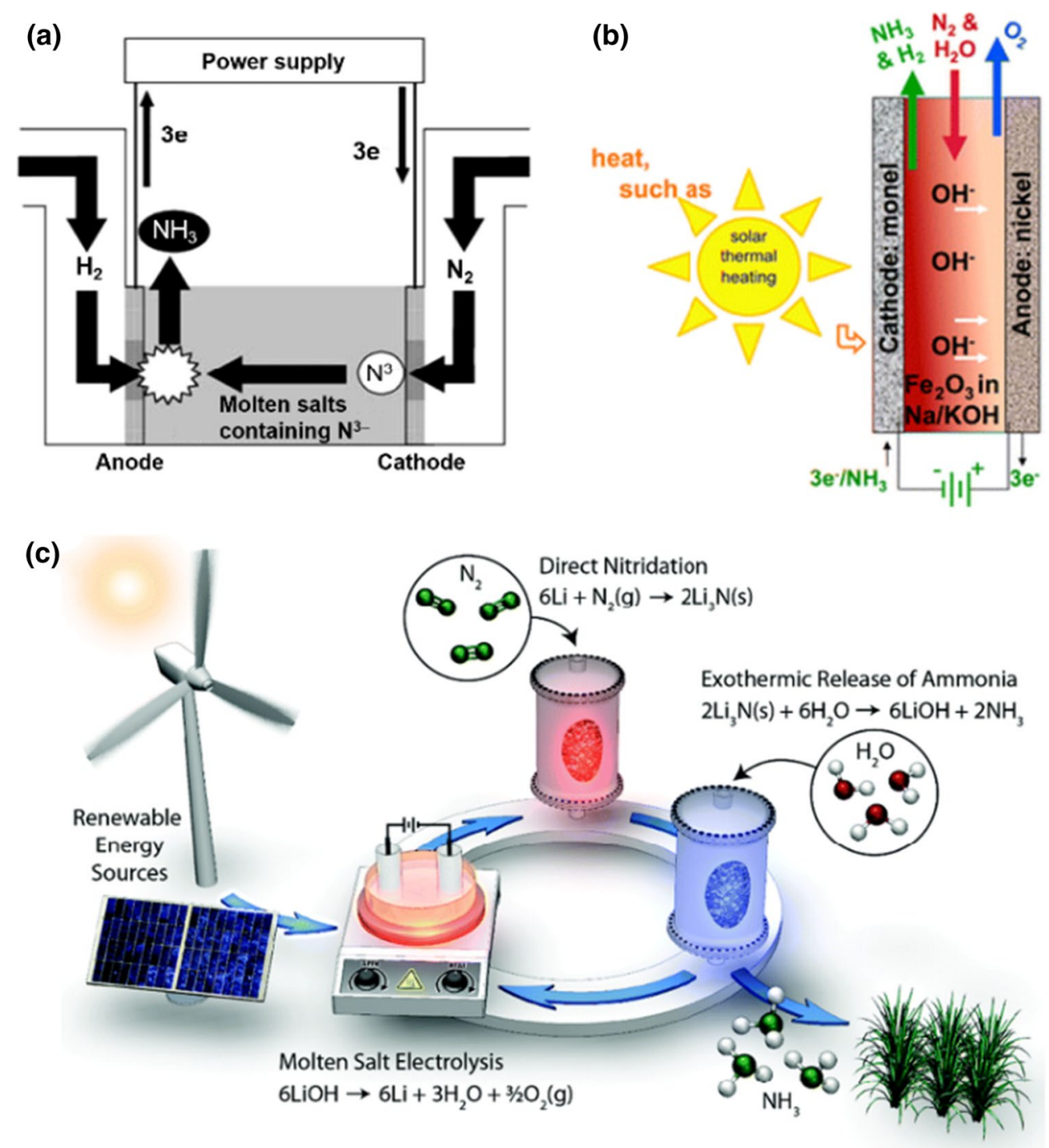

\section{Electrochemical Ammonia Synthesis in Liquid Electrolytes}

Low-temperature electrochemical $\mathrm{NH}_{3}$ synthesis in liquid or aqueous electrolytes has attracted considerable research attention. On the one hand, $\mathrm{NH}_{3}$ production at low $\mathrm{RT}$ could substantially reduce the energy consumption. On the other hand, ubiquitous $\mathrm{H}_{2} \mathrm{O}$ is used as the proton source instead of $\mathrm{H}_{2}$, which reduces the process cost and inhibits greenhouse gas emission fundamentally. Solid or molten salt electrolytemediated $\mathrm{N}_{2}$ reduction systems contain limited or zero water molecules, resulting in an insignificant hydrogen evolution. Therefore, research on $\mathrm{NH}_{3}$ synthesis in solid or molten salt media mainly focuses on electrolytes and the system design to reduce operating temperatures and enhance ion conductivity. In liquids, especially aqueous media, however, the abundance of water results in an extremely competitive electrolysis to hydrogen. In theory, given a highly active electrocatalyst, NRR can proceed in a narrow region of negative potentials without inducing $\mathrm{H}_{2} \mathrm{O}$ reduction (line a in Fig. 4) at any $\mathrm{pH}$ condition [22]. However, most electrocatalysts have an insufficient activity toward NRR. Therefore, $\mathrm{NH}_{3}$ could only be generated at more negative potentials than water reduction, where most electrons would favor $\mathrm{H}_{2}$ generation. Normally, the current efficiency of $\mathrm{NH}_{3}$ production in aqueous electrolyte hardly exceeds $5 \%$. The selectivity challenge necessitates the delineation of a mechanistic understanding of catalytic dinitrogen reduction to ammonia, based on which efficient heterogeneous electrocatalysts could be reasonably designed.

\section{Reaction Mechanisms}

The hydrogenation of $\mathrm{N}_{2}$ to $\mathrm{NH}_{3}$ on heterogeneous catalysts can be divided into dissociative and associative mechanisms (Fig. 5) [69, 70]. As for the dissociative mechanism, the $\mathrm{N} \equiv \mathrm{N}$ molecule is cleaved into adsorbed atomic nitrogen, which is subsequently hydrogenated to 


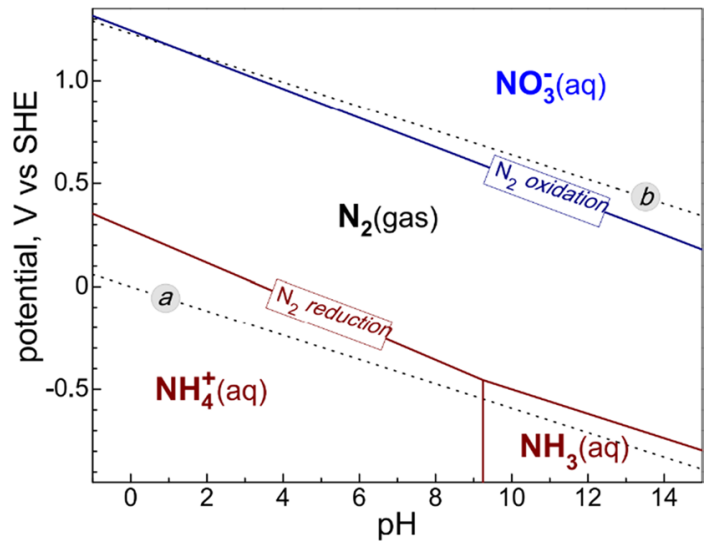

Fig. 4 Partial Pourbaix diagram for the $\mathrm{N}_{2}-\mathrm{H}_{2} \mathrm{O}$ system. Red line represents $\mathrm{N}_{2}$ reduction to $\mathrm{NH}_{4}{ }^{+}$or $\mathrm{NH}_{3}$, whereas blue line denotes $\mathrm{N}_{2}$ oxidation to $\mathrm{NO}_{3}{ }^{-}$. Dotted lines a and $\mathrm{b}$ represent $\mathrm{H}_{2} \mathrm{O}$ reduction to $\mathrm{H}_{2}$ and oxidation to $\mathrm{O}_{2}$, respectively. Reproduced with permission from Ref. [22]. Copyright 2018, AAAS

generate $\mathrm{NH}_{3}$ (Fig. 5a). Dissociative pathway is assumed to dominate ammonia synthesis in $\mathrm{H}-\mathrm{B}$ process, where the nitrogen chemisorption/dissociation is considered as the rate-determining step [71]. In the associative pathway, protonation on adsorbed $\mathrm{N}_{2}$ primarily occurs. The $\mathrm{N}-\mathrm{N}$ linkage is maintained during the initial reduction steps. Based on the hydrogenation sequences on two nitrogen atoms in
$\mathrm{N}_{2}$, the associative mechanism can be specifically assigned to the distal or alternating pathways. In the distal pathway (Fig. 5b), hydrogenation is asymmetric: the distal (relative to the substrate) nitrogen atom is hydrogenated first until one $\mathrm{NH}_{3}$ molecule is released, followed by subsequent hydrogenation on the proximal nitrogen atom and the second $\mathrm{NH}_{3}$ release. In the alternating pathway (Fig. 5c), the two $\mathrm{N}$ atoms are hydrogenated simultaneously (symmetrically) until $\mathrm{NH}_{3}$ is released, which is analogous to the mechanism of nitrogenase [6].

In a particular electrocatalytic system of NRR, the explicit pathways (Fig. 5) remain obscure. Density functional theory (DFT) is often used to calculate the free energy changes of possible intermediates and delineate the possible mechanism on specific catalysts. For example, Nørskov's group [72] systematically evaluated the electrocatalytic activity of $\mathrm{NH}_{3}$ formation on both flat and stepped surfaces of a range of transition metals. Based on the approximate linear relations between the adsorption energies of nitrogen-containing intermediates $\mathrm{NH}_{x} / \mathrm{N}_{2} \mathrm{H}_{x}$ and the chemisorption energy of $\mathrm{N}$-adatom, the free energy changes in elementary reactions $(\Delta G)$ were calculated, and the rate-limiting $\Delta G$ reflected the onset potential $(U)$ for $\mathrm{NH}_{3}$ synthesis. Combined volcano diagrams were plotted $[72,73]$ to show the estimated onset potential as a function of the nitrogen-binding energy for dissociative (solid lines)
Fig. 5 Nitrogen reduction pathways on heterogeneous catalysts. a Dissociative pathway where $\mathrm{N} \equiv \mathrm{N}$ bond is broken before hydrogenation. Associative pathways including $\mathbf{b}$ distal or asymmetric hydrogenation and $\mathbf{c}$ alternating or symmetric hydrogenation. Adapted with permission from Ref. [70]. Copyright 2014, The Royal Society of Chemistry
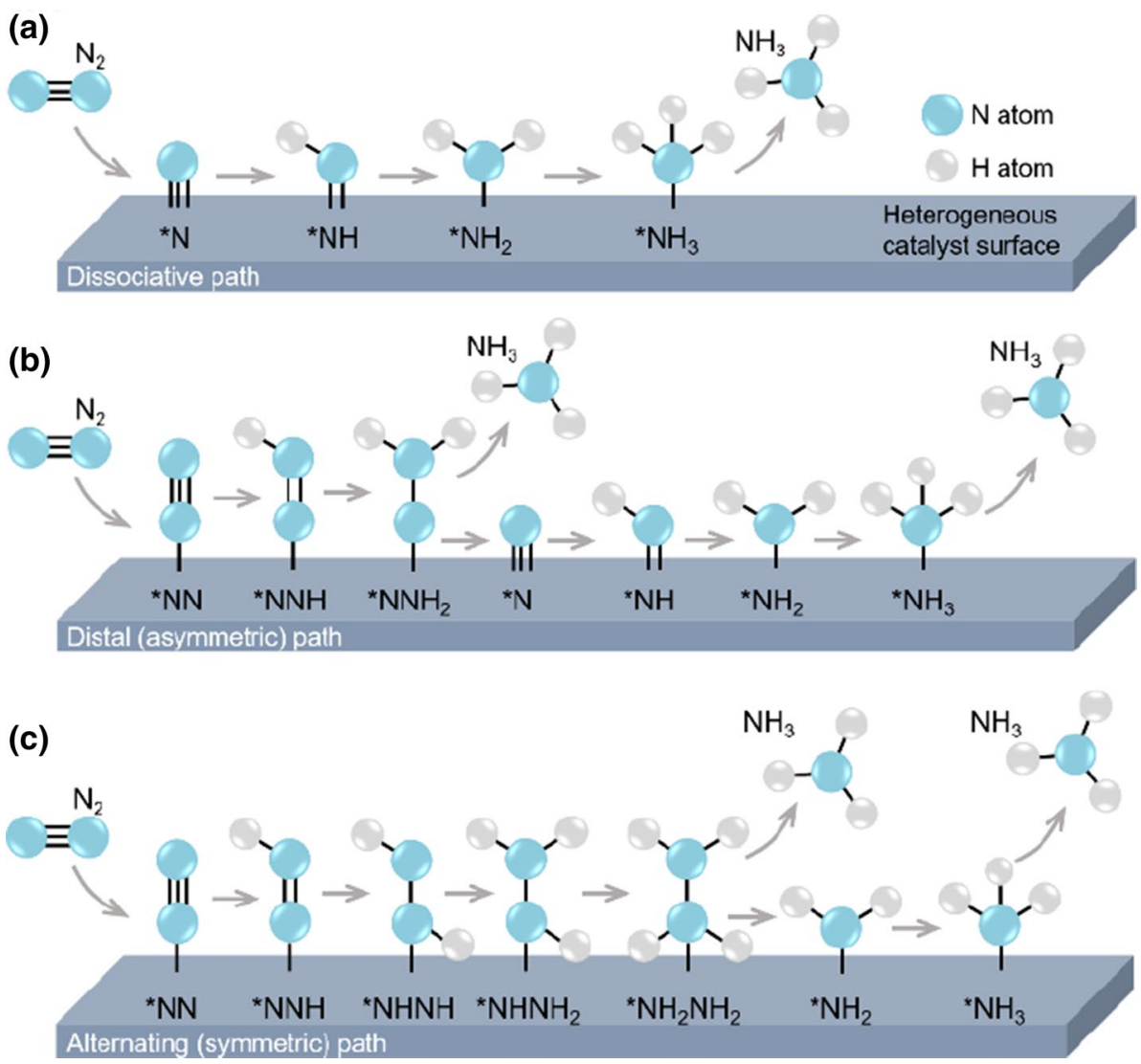
and associative (dashed lines) mechanisms on either flat (blue) or stepped (red) surfaces (Fig. 6). On the left sides of the volcanoes, the dissociative pathway dominates, and the onset potential for $\mathrm{NH}_{3}$ formation is slightly more positive on the flat surfaces than that on the stepped ones. This slight difference is attributed to the smaller free energy change from $* \mathrm{NH}$ to $* \mathrm{NH}_{2}$ (rate-limiting step on flat surfaces) than that from $* \mathrm{NH}_{2}$ to $\mathrm{NH}_{3}$ (rate-limiting step on stepped surfaces). On the right sides of the volcanoes, $\mathrm{N}_{2}$ splitting is the rate-limiting step for dissociative mechanism on either flat or stepped surfaces (overlapped as black solid line) due to the same free energy change from $\mathrm{N}_{2}$ to $* 2 \mathrm{~N}$, whereas the first hydrogenation step on adsorbed $\mathrm{N}_{2}$ determines the onset potential for the associative mechanism (blue and red dashed lines). Different transition metals prefer different reaction pathways. Reactants on early transition metals ( $\mathrm{Sc}$ to $\mathrm{Fe}$; $\mathrm{Y}$ to $\mathrm{Ru}$ ) follow a dissociative pathway with one of the hydrogenation reactions as the rate-limiting step. Several late transition metals prefer a dissociative mechanism with $\mathrm{N}_{2}$ splitting as the limiting step ( $\mathrm{Rh}, \mathrm{Ir}, \mathrm{Co}$ and $\mathrm{Ni}$ ), whereas others prefer an associative mechanism at more negative potentials $(\mathrm{Pd}, \mathrm{Cu}, \mathrm{Ag}$ and $\mathrm{Au}$ ). Notably, the surfaces in most part of the diagrams are dominated by $\mathrm{H}$-adatoms, resulting in the rapid formation of $\mathrm{H}_{2}$ other than $\mathrm{N}_{2}$. Ru and Rh with theoretically the highest activity (top of volcano diagrams) exhibit poor selectivity due to strong $\mathrm{H}$ adsorption. Only the flat metal surfaces of Sc, Y, Ti and $\mathrm{Zr}$ (shaded green area) are assumed to be covered by $\mathrm{N}$ instead of $\mathrm{H}$. However, the strong binding of $\mathrm{N}$ might lead to the difficult desorption of reaction intermediates.

Theoretical screening provides limited guidance for catalyst design. The actual surface environment on the catalyst could occasionally be located distantly from that in calculations. For example, surface reconstruction occurs during reactions, and certain metal catalysts would form surface oxide layers under reduction potentials. Nanosized catalysts also have more complexed exposed faces and defects than their bulk counterparts [74-79]. In recent years, various electrocatalysts have been explored for $\mathrm{NH}_{3}$ synthesis from $\mathrm{N}_{2}$ and $\mathrm{H}_{2} \mathrm{O}$ in liquid or aqueous media [80].

\section{Metal Catalysts}

Thus far, limited experimental reports are available regarding electrochemical NRR (ENRR) on metal bulks or films in aqueous media. One chemically deposited Au thin-film electrode produced $\mathrm{NH}_{3}$ at potentials below $0 \mathrm{~V}$ versus reversible hydrogen electrode $\left(\mathrm{V}_{\mathrm{RHE}}\right)$ [81]. The authors used surface-enhanced infrared absorption spectroscopy (SEIRAS) to successfully detect $\mathrm{N}_{2} \mathrm{H}_{x}$ species in the reaction process. The current efficiency was $0.12 \%$, and the $\mathrm{NH}_{3}$ formation rate reached $3.84 \times 10^{-12} \mathrm{~mol} /\left(\mathrm{cm}^{2} \mathrm{~s}\right)$ at $-0.5 \mathrm{~V}_{\mathrm{RHE}} . \mathrm{N}_{2} \mathrm{H}_{x}$ intermediates indicated an associative mechanism on $\mathrm{Au}$, which is consistent with the calculations in Fig. 6. A parallel experiment on Pt film showed no intermediate absorption bands under the same conditions. Another active metal film reported is a (110) orientation Mo, which achieved a current efficiency of $0.72 \%$ for $\mathrm{NH}_{3}$ generation [82].

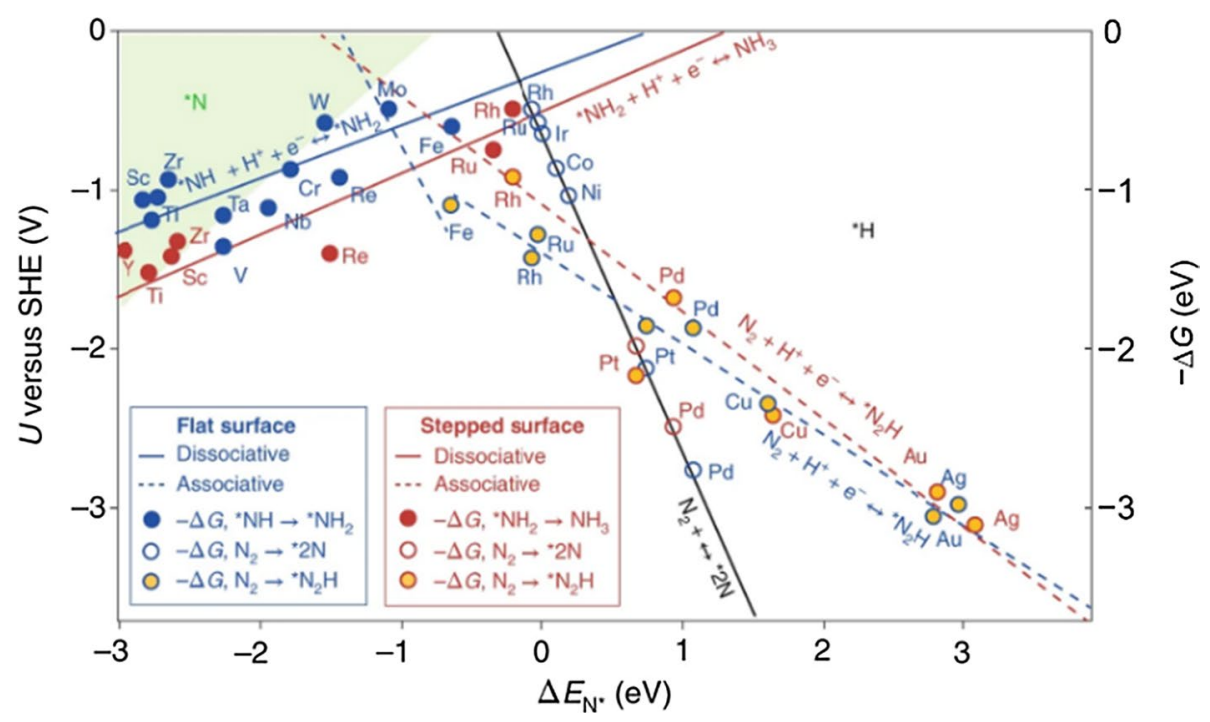

Fig. 6 Combined volcano diagrams evaluating onset potential $(U)$ on different transition metals. Solid lines represent dissociative mechanisms, and dashed lines denote associative ones. Blue and red lines represent reactions on flat and stepped surfaces, respectively. Black line indicates an overlap between blue and red lines. The green shaded area indicates the region where surface is likely to be covered by adsorbed nitrogen, and white area denotes the region where surface is likely to be covered by adsorbed hydrogen. Adapted with permission from Refs. [72] and [73]. Copyright 2012, The Royal Chemical Society. Copyright 2019, Macmillan Publishers Limited 
More active results were observed on nanosized metal catalysts. Yan and colleagues [83-85] tested a series of $\mathrm{Au}$ electrocatalysts with different nanostructures. Tetrahexahedral (THH) Au nanorods (NRs) by a seeded growth method showed good electrocatalytic $\mathrm{N}_{2}$ reduction performance in $0.1 \mathrm{~mol} / \mathrm{L} \mathrm{KOH} \mathrm{[83].} \mathrm{THH-Au} \mathrm{NRs} \mathrm{exposed} \mathrm{abundant}$ high-index facets of (310) and (210), which facilitated $\mathrm{N}_{2}$ activation and reduction. The $\mathrm{THH}-\mathrm{Au}$ achieved the highest ammonia production rate of $2.69 \times 10^{-11} \mathrm{~mol} /\left(\mathrm{cm}^{2} \mathrm{~s}\right)$ at $-0.2 \mathrm{~V}_{\mathrm{RHE}}$ with a current efficiency of $\sim 4 \%$. Although highindex faces on $\mathrm{THH}-\mathrm{Au}$ play important roles in $\mathrm{N}_{2}$ reduction, the relatively large size of NRs ( $\sim 50 \mathrm{~nm}$ in length) restricts the atomic utilization. Subnanometer Au clusters $(0.5 \mathrm{~nm})$ on $\mathrm{TiO}_{2}$ support showed enhanced electrocatalytic NRR, where the low-coordination sites on small Au clusters are considered crucial. An ammonia production rate of $1.12 \times 10^{-10} \mathrm{~mol} /\left(\mathrm{cm}^{2} \mathrm{~s}\right)$ with a current efficiency of $8.11 \%$ was achieved at $-0.2 \mathrm{~V}_{\mathrm{RHE}}$ [84]. Amorphous nanocatalysts with highly unsaturated coordination sites are occasionally more active than the crystalline ones in catalysis. This condition is illustrated by anchored amorphous $\mathrm{Au}$ nanoparticles (a-Au NPs, $\sim 5 \mathrm{~nm}$ ) on a bisubstrate of $\mathrm{CeO}_{x} /$ reduced graphene oxide $\left(\mathrm{CeO}_{x}-\mathrm{RGO}\right)$, where $\mathrm{CeO}_{x}$ transforms the crystallized $\mathrm{Au}$ into its amorphous form, and RGO acts as the substrate to anchor and disperse the Au NPs [85]. The obtained a-Au/ $\mathrm{CeO}_{x}$ - $\mathrm{RGO}$ exhibited a current efficiency of $10.1 \%$, which was considerably higher than that of crystalline Au on RGO.

On a carbon-supported nano-Pd catalyst, an overpotential as low as $56 \mathrm{mV}$ was reported for $\mathrm{N}_{2}$ reduction [86]. $\alpha$-Palladium hydride was assumed to form during reaction and to lower the free energy barrier of $\mathrm{N}_{2}$ hydrogenation to $* \mathrm{~N}_{2} \mathrm{H}$, the rate-limiting step for $\mathrm{NH}_{3}$ electrosynthesis. A current efficiency of $8.2 \%$ was attained at $0.1 \mathrm{~V}_{\text {RHE}}$.

A record-breaking activity and selectivity for ENRR at ambient conditions were recently realized on a main-group metal bismuth nanocrystals with $\mathrm{K}^{+}$promoters in aqueous electrolyte [87]. At the optimum potential of $-0.6 \mathrm{~V}_{\mathrm{RHE}}$, the $\mathrm{NH}_{3}$ generation rate reached as high as $1.44 \times 10^{-8} \mathrm{~mol} /$ $\left(\mathrm{cm}^{2} \mathrm{~s}\right)$ with a remarkable current efficiency of $66 \%$. This production rate outperforms other works of ENRR in aqueous media by one to three orders of magnitude and parallels the levels in molten salt electrolyte cells operating at elevated temperature or pressure. During the long-term operation of up to $50 \mathrm{~h}$, the Bi nanocrystal catalyst retained its activity and metallic state. The authors proposed a distal pathway of associative mechanism (Fig. 5b), with the reductive protonation of $\mathrm{N}_{2}$ to $* \mathrm{NNH}$ as the rate-limiting step. The projected density of states revealed a remarkable overlap between $2 p$ orbitals of adsorbed $\mathrm{N}$ and $\mathrm{Bi} 6 p$ bands both below and above the Fermi level. By comparison, $\mathrm{Au}$ as a transition metal showed minimal overlap between its $5 d$ band and $\mathrm{N} 2 p$ orbital. Therefore, a stronger interaction existed between Bi surface and *NNH intermediate, whose formation energy barrier $\left(\Delta G_{* \mathrm{NNH}}\right)$ was considerably lower compared with that on $\mathrm{Au}$ (Fig. 7a). More importantly, $\mathrm{K}^{+}$acted as a strong promoter in this system, boosting the current efficiency from $9.8 \%$ to $67 \%$. On the one hand, $\mathrm{K}^{+}$ shifted the $2 p$ orbital of adsorbed $\mathrm{N}$ to lower energy and decreased $\Delta G_{* \mathrm{NNH}}$ (Fig. $7 \mathrm{~b}$ ), leading to a stronger $\mathrm{Bi}-\mathrm{N}$ bond and a better $\mathrm{N}-\mathrm{N}$ activation. On the other hand, highconcentration $\mathrm{K}^{+}$hindered proton migration from the bulk solution to the Bi electrode surface, suppressing HER and enhancing ENRR selectivity (Fig. 7c, d, respectively).
Fig. 7 Boosting ENRR with Bi metal catalysts and $\mathrm{K}^{+}$ cations. a Free energy changes $\left(\Delta G_{* N N H}\right)$ for the ratelimiting step forming * $\mathrm{NNH}$ $\left(*+\mathrm{N}_{2}+\mathrm{H}^{+}+\mathrm{e}^{-} \rightarrow * \mathrm{NNH}\right)$ on $\mathrm{Bi}$ (012), (110), (104), and $\mathrm{Au}$ (111) facets. b $\Delta G_{* \mathrm{NNH}}$ on $\mathrm{Bi}$ (012), (110), and (104) facets without (patterned bars) and with (filled bars) $\mathrm{K}^{+}$. Mass transfer of $\mathrm{H}^{+}$and $\mathrm{N}_{2}$ to the catalyst surface in electrolytes without $\mathbf{c}$ and with $\mathbf{d} \mathrm{K}^{+}$. Adapted with permission from Ref. [87]. Copyright 2019, Macmillan Publishers Limited

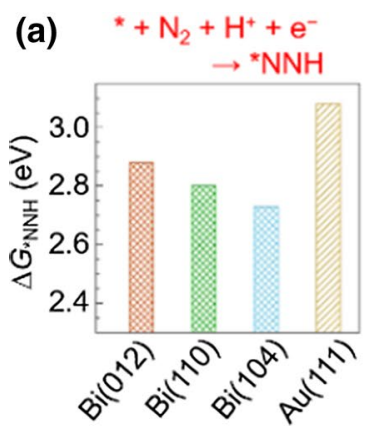

(c)
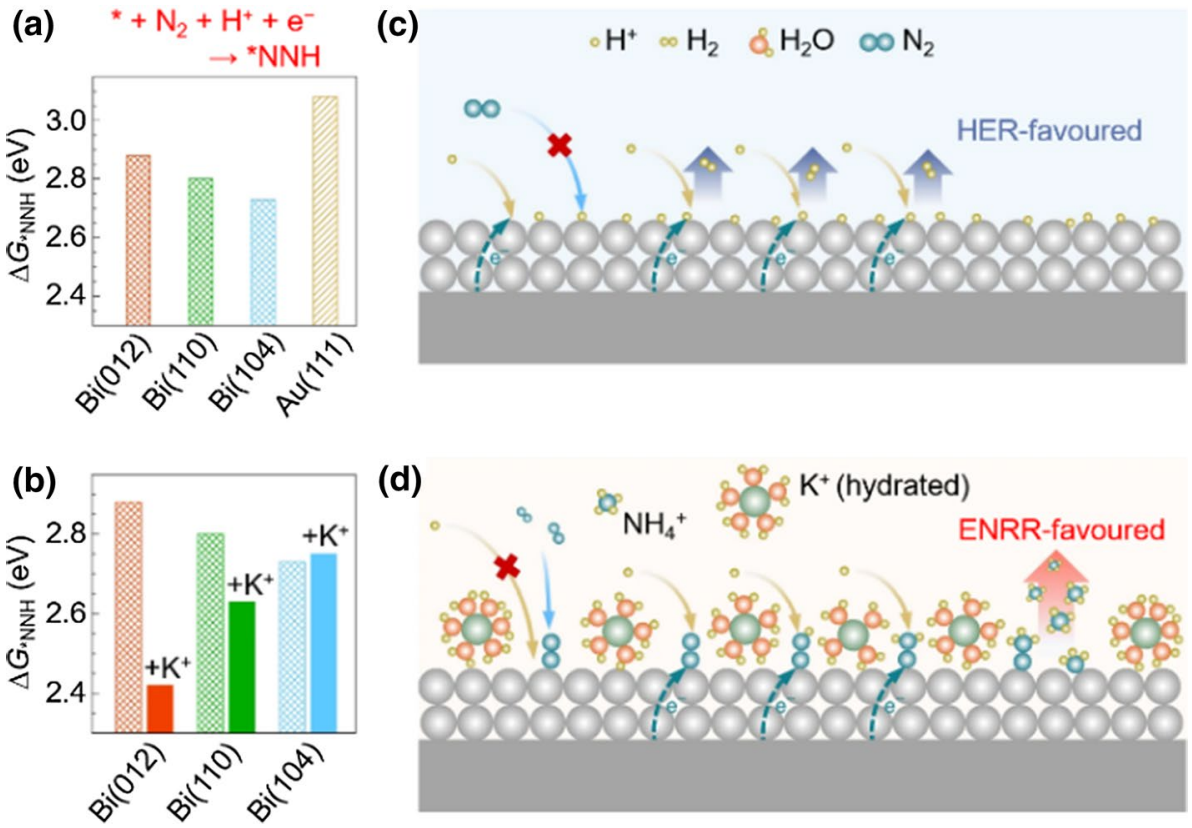

(d)

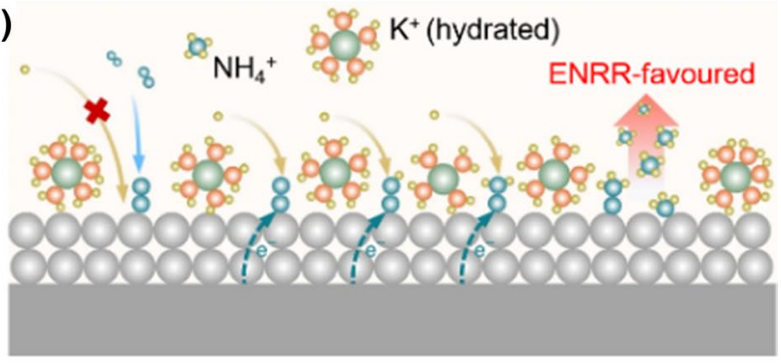


As illustrated in the "Reaction Mechanisms" section, the electrocatalytic conversion of $\mathrm{N}_{2}$ to $\mathrm{NH}_{3}$ on transition metal relies on the linear scaling relationship between $* \mathrm{~N}_{2} \mathrm{H}$ and $* \mathrm{NH}_{2}$. The overpotentials of ENRR are larger than those of HER, leading to the limited success of NRR on transition metals. Metal alloys might be an approach to meet this challenge because of their synergetic interactions with the absorbed intermediates. Nonetheless, alloys cannot break the scaling relationship for $* \mathrm{~N}_{2} \mathrm{H}$ and $* \mathrm{NH}_{2}$, as each kind of metal bonds to the intermediates through a single $\mathrm{N}$ atom. How to design the active sites to change the intermediates' binding modes remains an important question.

\section{Metal Compound Catalysts}

As mentioned in the "Electrochemical Ammonia Synthesis in Molten Electrolytes" section, nano- $\mathrm{Fe}_{2} \mathrm{O}_{3}$ shows excellent electrocatalytic performance for NRR in molten base electrolyte, but the possible mechanism was not discussed [36]. A DFT study on hematite (0001) revealed an associative pathway where the potential demanding step is * $\mathrm{NNH}$ formation from $\mathrm{N}_{2}$ [88]. The calculated applied bias needed is $-1.1 \mathrm{~V}$, which is consistent with the conducted $1.2 \mathrm{~V}$ for nano- $\mathrm{Fe}_{2} \mathrm{O}_{3}$ [36]. Apart from molten electrolytes, $\mathrm{Fe}_{2} \mathrm{O}_{3}$ electrocatalyst was also applied either in gas diffusion layer (GDL) electrode [89-91] or directly immersed in aqueous media [92]. Chen et al. [89, 91] studied carbon nanotubesupported iron oxide $\left(\mathrm{Fe}_{2} \mathrm{O}_{3}\right.$-CNT) as $\mathrm{N}_{2}$ reduction electrocatalyst on GDL electrode in a three-phase cell separated by a proton exchange membrane. The liquid chamber contained aqueous electrolyte for $\mathrm{H}_{2} \mathrm{O}$ electrolysis to produce $\mathrm{H}^{+}$and electrons. The protons migrated through proton exchange membrane to the GDL electrode, where $\mathrm{N}_{2}$ gas was reduced by electrons and hydrogenated to form $\mathrm{NH}_{3}$. The current densities were determined by proton concentration in acid electrolyte and by water transport in the base electrolyte. The $30 \% \mathrm{Fe}_{2} \mathrm{O}_{3}$-CNT was the best electrocatalyst among all $\mathrm{Fe}_{2} \mathrm{O}_{3}$-CNT samples [89]. Kong et al. [90] also investigated $\gamma-\mathrm{Fe}_{2} \mathrm{O}_{3}$ electrocatalyst for $\mathrm{NH}_{3}$ synthesis in a three-phase cell separated by an anion-exchange membrane. Using $\mathrm{KOH}$ electrolyte, the $\gamma-\mathrm{Fe}_{2} \mathrm{O}_{3}$ electrode achieved a current efficiency of $1.9 \%$ at $0 \mathrm{~V}_{\mathrm{RHE}}$.

Through an electrospinning/calcination method, a hybrid metal oxide $\mathrm{Bi}_{4} \mathrm{~V}_{2} \mathrm{O}_{11} / \mathrm{CeO}_{2}$ with an amorphous phase (BVC-A) was fabricated and used as the cathode for electrocatalytic nitrogen reduction [93]. The amorphous $\mathrm{Bi}_{4} \mathrm{~V}_{2} \mathrm{O}_{11}$ contains abundant oxygen vacancies $\left(\mathrm{O}_{\mathrm{vac}}\right)$, which acted as active sites for $\mathrm{N}_{2}$ reduction. $\mathrm{CeO}_{2}$ not only induced the amorphous structure but also established suitable band alignment with $\mathrm{Bi}_{4} \mathrm{~V}_{2} \mathrm{O}_{11}$ to facilitate interfacial charge transfer (Fig. 8a). A high current efficiency of $10.16 \%$ was achieved at $-0.2 \mathrm{~V}_{\mathrm{RHE}}$.

$\mathrm{MoS}_{2}$ as one hot-spot two-dimensional (2D) material has attractive catalytic properties. The $\mathrm{NH}_{3}$ formation by $\mathrm{MoS}_{2}$ was first reported in $0.1 \mathrm{~mol} / \mathrm{L} \mathrm{Na}_{2} \mathrm{SO}_{4}$ [94]. Defects on the monolayer of $\mathrm{MoS}_{2}$ boosted $\mathrm{N}_{2}$ reduction [95]. A DFT simulation assumed that single $\mathrm{Fe}$ atom deposited on $\mathrm{MoS}_{2}$ would mimic FeMoco and endow inactive $\mathrm{MoS}_{2}$ the capability to convert $\mathrm{N}_{2}$ to $\mathrm{NH}_{3}$ electrocatalytically. Fe center yields electron charge to $\mathrm{MoS}_{2}$ and turns into an
Fig. 8 ENRR on metal compound catalysts. a Interfacial charge transfer in BVC-A for ENRR. Reproduced with permission from Ref. [93]. Copyright 2018, Wiley-VCH. b $\mathrm{Ru} / \mathrm{MoS}_{2}$ catalyzes an ENRR process in which Ru cluster acts as an NRR active site, whereas S-vacancy of $\mathrm{MoS}_{2}$ acts as a hydrogenation site. Adapted with permission from Ref. [97]. Copyright 2019, American Chemical Society. c NRR pathway on the surface of $\mathrm{VN}_{0.7} \mathrm{O}_{0.45}$ via a Mars-van Krevelen (MvK) mechanism and the catalyst deactivation mechanism. Adapted with permission from Ref. [104]. Copyright 2018, American Chemical Society
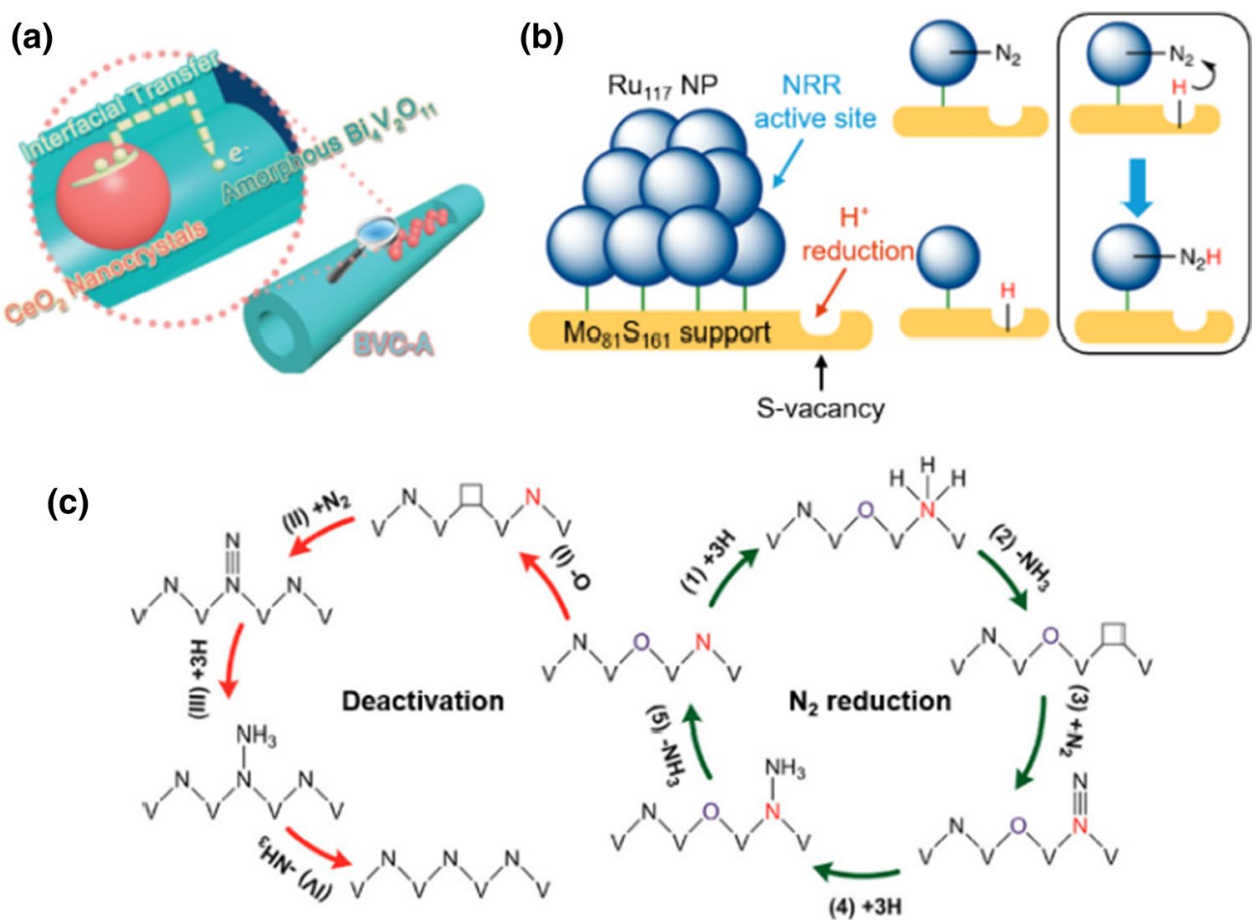
extremely rare and reactive $\mathrm{Fe}^{\mathrm{I}}$ species [96]. Interestingly, $\mathrm{Ru}$ instead of $\mathrm{Fe}$ on $\mathrm{MoS}_{2}$ was experimentally discovered as an active catalyst for ENRR [97]. As shown previously in Fig. 6, Ru is near the top of volcano plot but exhibits considerable hydrogen evolution due to dominant $\mathrm{H}$ adsorption. In the work on $\mathrm{Ru} / \mathrm{MoS}_{2}$ [97], dispersed $\mathrm{Ru}$ clusters provide $\mathrm{N}_{2}$-binding sites, whereas nearby $\mathrm{S}$-vacancies on the $2 \mathrm{H}-\mathrm{MoS}_{2}$ serve as centers for $\mathrm{H}^{+}$reduction to adsorbed $* \mathrm{H}$ (Fig. 8b). These hydrogenated S-vacancies act as the $\mathrm{H}$-provider because the formed ${ }^{*} \mathrm{H}$ can be transferred directly to nearby $\mathrm{N}_{2}$ on $\mathrm{Ru}$, forming $* \mathrm{NNH}$ as an intermediate. The $* \mathrm{NNH}$ was unstable on $\mathrm{Ru} / \mathrm{MoS}_{2}$ and spontaneously cleaved into $* \mathrm{~N}$ and $* \mathrm{NH}$, following which a dissociative pathway was proposed.

$\mathrm{M}_{3} \mathrm{C}_{2}$ transition metal carbides ( $\mathrm{M}$ stands for metals from $\mathrm{d}^{2}, \mathrm{~d}^{3}$ and $\mathrm{d}^{4}$ series), as a kind of Mxene, have shown capabilities for $\mathrm{N}_{2}$ capture and reduction in a DFT study [98]. $\mathrm{V}_{3} \mathrm{C}_{2}$ and $\mathrm{Nb}_{3} \mathrm{C}_{2}$ exhibited the most promising features for reduction to $\mathrm{NH}_{3}$. In another metal carbide system, $\mathrm{Mo}_{2} \mathrm{C}$ nanodots embedded in carbon nanosheets were developed for electrochemical nitrogen fixation [99]. At $-0.3 \mathrm{~V}_{\mathrm{RHE}}$, the $\mathrm{NH}_{3}$ production rate reached $11.3 \mu \mathrm{g} /$ (h $\mathrm{mg}$ ). Carbon-supported $\mathrm{Mo}_{2} \mathrm{C}$ is proposed to be rich in nitrogen adsorption active sites, and the unique electronic structure is favorable to $\mathrm{N} \equiv \mathrm{N}$ bond cleavage and hydrogenation.

Transition metal nitrides draw great attention because they have the potential to activate adsorbed $\mathrm{N}_{2}$ via the $\mathrm{MvK}$ mechanism [100-103]. Specifically, one surface $\mathrm{N}$ atom on the nitride is hydrogenated and reduced to one $\mathrm{NH}_{3}$ molecule, forming a lattice vacancy which is subsequently restored by reductive incorporation of a $\mathrm{N}_{2}$ molecule. One good example was demonstrated by vanadium nitride (VN) NPs, where surface $\mathrm{VN}_{0.7} \mathrm{O}_{0.45}$ acted as the active phase [104]. The use of ${ }^{15} \mathrm{~N}_{2}$ feed gas produced ${ }^{14} \mathrm{NH}_{3}$ and ${ }^{15} \mathrm{NH}_{3}$, indicating a $\mathrm{MvK}$ mechanism. In a catalytic cycle, a native surface $\mathrm{N}$ atom of $\mathrm{VN}$ was extracted by hydrogen atoms and left behind a $\mathrm{N}$ vacancy $\left(\mathrm{N}_{\mathrm{vac}}\right)$, which could activate/ adsorb a $\mathrm{N}_{2}$ molecule and be healed after the desorption of one $\mathrm{NH}_{3}$ molecule. Moreover, only the surface $\mathrm{N}$ sites adjacent to a surface $\mathrm{O}$ are active toward nitrogen reduction, and the removal of surface $\mathrm{O}$ would deactivate the catalyst (Fig. 8c). The 2D MoN material is also a promising candidate for ENRR in theoretical and experimental demonstrations $[105,106]$.

As illustrated, in metal compound catalysts, introducing anion vacancies, such as oxygen, nitrogen, sulfur and selenium vacancies, plays an important role in ENRR. The anion vacancies could trap metastable electrons, which are transported into an antibonding orbital of adsorbed $\mathrm{N}_{2}$ molecules, contributing to enhancing nitrogen triple-bond cleavage for subsequent catalytic reaction. The regeneration capability of vacancies during reaction needs further investigation.

\section{Metal-Free Catalysts}

Scalable hierarchically structured nitrogen-doped nanoporous carbon membranes with embedded CNTs were developed for ENRR [107]. In this hierarchically porous membrane structure, micropores and small mesopores provided large and accessible surface areas up to $432 \mathrm{~m}^{2} / \mathrm{g}$. Meanwhile, large mesopores and macropores formed interconnected 3D conductive framework to expedite mass diffusion and enhanced $\mathrm{N}_{2}$ reduction efficiency on active sites, which are proposed to be pyridinic and pyrrolic $\mathrm{N}$ atoms in N-doped carbons [107, 108].

A polymeric carbon nitride ( $\mathrm{PCN}$ ) abundant in $\mathrm{N}_{\mathrm{vac}}$ was proposed as an electrocatalyst to enable ammonia synthesis under ambient conditions [109]. DFT calculations illustrated that dinitrogen molecule can be chemisorbed on $\mathrm{N}_{\mathrm{vac}}$ of PCN in a dinuclear end-on bound structure, which dramatically increases $\mathrm{N}-\mathrm{N}$ bond length and improves spatial electron transfer. A high current efficiency of $11.59 \%$ was therefore obtained at $-0.2 \mathrm{~V}_{\mathrm{RHE}}$, leading to an ammonia production rate of $9.64 \times 10^{-10} \mathrm{~mol} /\left(\mathrm{cm}^{2} \mathrm{~s}\right)$.

Black phosphorus (BP) with a few layers of nanosheet structure is a nonmetallic electrocatalyst for nitrogen reduction under ambient conditions [110]. DFT calculations propose an alternating hydrogenation pathway. The zigzag and diff-zigzag edges of BP are active centers for nitrogen adsorption and activation.

\section{Battery Configurations for NRR}

In addition to electrolysis, proof-of-concept batteries have led to new directions toward $\mathrm{N}_{2}$ fixation. Minteer and colleagues [111] combined nitrogenase and hydrogenase into a $\mathrm{H}_{2} / \mathrm{N}_{2}$ fuel cell, with a 3-morpholinopropane-1-sulfonic acid buffer as the electrolyte (Fig. 9). The electron transfer between cathode/nitrogenase and anode/hydrogenase was realized by using methyl viologen ( $\mathrm{MV}, N, N^{\prime}$-dimethyl$4,4^{\prime}$-bipyridinium) as the sole electron donor. The coupling of this nitrogenase cathode to reduce $\mathrm{N}_{2}$ with a hydrogenase anode to oxidize $\mathrm{H}_{2}$ resulted in an enzyme-assisted fuel cell (EFC), generating $\mathrm{NH}_{3}$ from $\mathrm{H}_{2}$ and $\mathrm{N}_{2}$ while simultaneously outputting an electrical current. A current efficiency of $26.4 \%$ was obtained on this $\mathrm{H}_{2} / \mathrm{N}_{2}$ EFC. Ma et al. [112] reported a successful illustration of a reversible nitrogen cycle based on a rechargeable lithium-nitrogen $\left(\mathrm{Li}-\mathrm{N}_{2}\right)$ battery with the proposed reversible reaction of $6 \mathrm{Li}+\mathrm{N}_{2} \rightleftharpoons 2 \mathrm{Li}_{3} \mathrm{~N}$. The $\mathrm{N}_{2}$ fixation battery assembly was composed of a lithium anode, an ether-based electrolyte, and a carbon cloth cathode and exhibited a promising electrochemical current efficiency of 59\%. 
Fig. 9 Incorporation of hydrogenase and nitrogenase proteins into a $\mathrm{H}_{2} / \mathrm{N}_{2}$ fuel cell with $\mathrm{MV}$ as the electron mediator in both chambers. This fuel cell produces $\mathrm{NH}_{3}$ and electrical energy from $\mathrm{H}_{2}$ and $\mathrm{N}_{2}$ at RT and ambient pressure. Reproduced with permission from Ref. [111]. Copyright 2017, Wiley-VCH

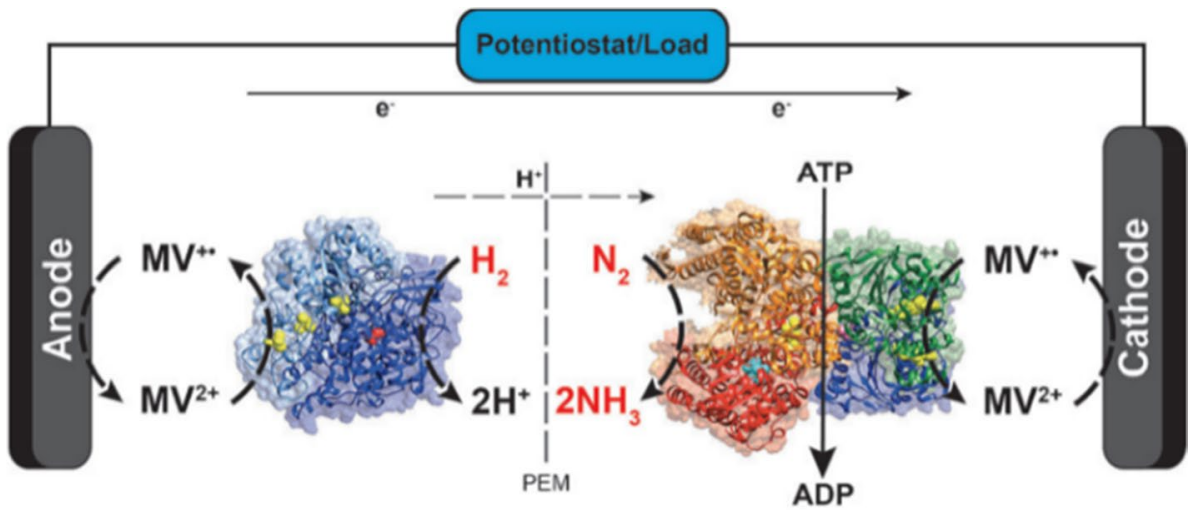

\section{Methods to Suppress HER}

In protic (e.g., aqueous) electrolytes, HER is a serious competitive reaction that greatly restricts the selectivity of $\mathrm{N}_{2}$ reduction to $\mathrm{NH}_{3}$ in the presence of protons. For example, recent publications [83-86, 93, 109, 113-115] reported electrochemical $\mathrm{NH}_{3}$ synthesis in aqueous solutions: The highest current efficiency for $\mathrm{NH}_{3}$ and the highest $\mathrm{NH}_{3}$ production rate depend on small applied potentials, whereas further enlarged negative potentials result in a significantly reduced current efficiencies and $\mathrm{NH}_{3}$ production rates (Fig. 10). -0.2 $\mathrm{V}_{\mathrm{RHE}}$ is the most frequently reported potential [83-85, 93, $109,113,114]$ at which the fastest $\mathrm{NH}_{3}$ generation is attained (Fig. 10a-c). For a palladium-catalyzed $\mathrm{N}_{2}$ reduction system, the highest current efficiency of $8.2 \%$ was achieved at as high as $0.1 \mathrm{~V}_{\text {RHE }}$ (Fig. 10d) [86]. At such small applied potentials, the current densities are in the range of several hundred microamperes to several microamperes, which are inapplicable to practical applications. This effect could be amplified when current densities are larger.

Nørskov and colleagues [116] presented in-depth perspectives on the selectivity challenges for electrochemical $\mathrm{NH}_{3}$ synthesis. They suggested that limiting either proton or electron availability at the surface is a promising way to improve the selectivity of $\mathrm{NH}_{3}$. Detailed methods include limiting the proton transfer rates by reducing proton concentration in the electrolyte or increasing proton transfer barriers to the catalyst surface or limiting the electron transfer rates by constructing thin insulators or supplying slow streams of electrons.

By reducing proton concentration using ionic liquids as the electrolytes, MacFarlane and coworkers [117]
Fig. 10 Low selectivity of $\mathrm{NH}_{3}$ in ENRR compared with $\mathrm{H}_{2}$ generation, shown by the yield and current efficiency of $\mathrm{NH}_{3}$ at various potentials on different electrocatalysts. a BVC-A. Adapted with permission from Ref. [93]. Copyright 2018, Wiley-VCH. b a-Au/CeO ${ }_{x}$ RGO. Adapted with permission from Ref. [85]. Copyright 2017, Wiley-VCH. c $\mathrm{Pd}_{0.2} \mathrm{Cu}_{0.8} / \mathrm{rGO}$. Adapted with permission from Ref. [114]. Copyright 2018, Wiley-VCH. d Pd/C. Adapted with permission from Ref. [86]. Copyright 2018, Macmillan Publishers Limited (a)

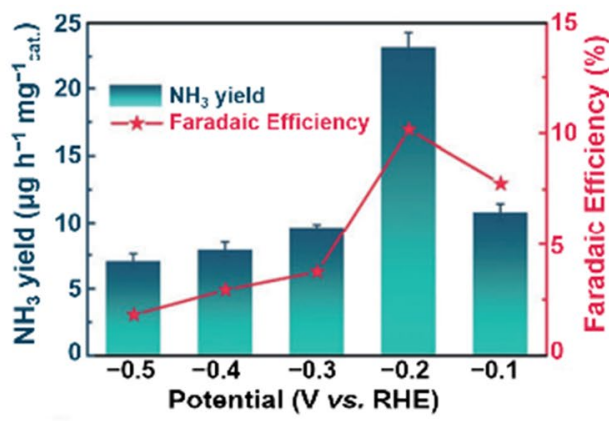

(c)

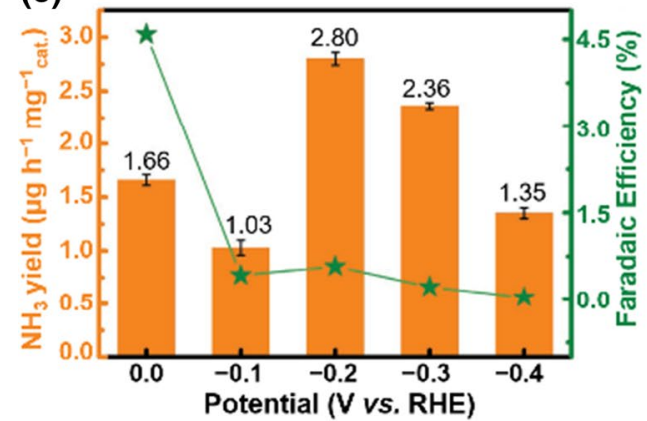

(b)
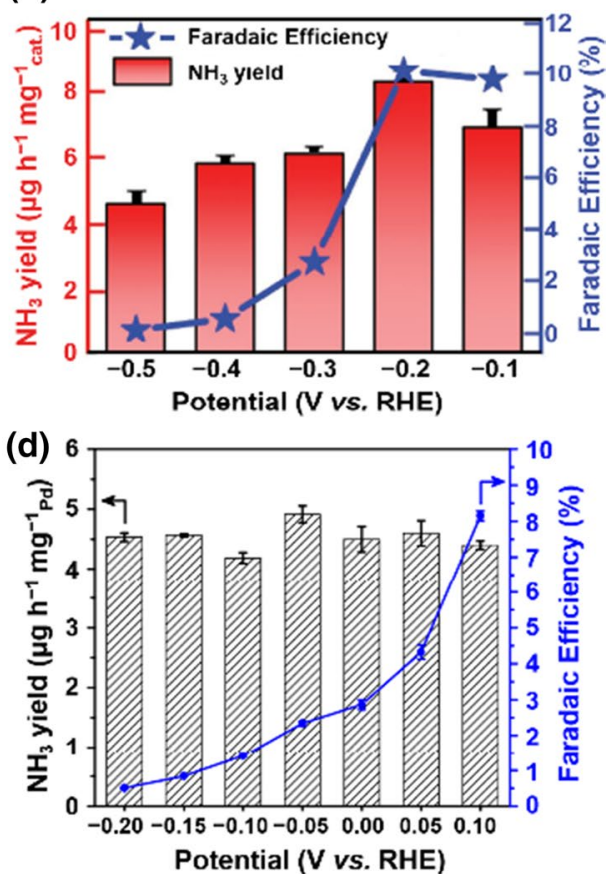
reported a highly selective system for $\mathrm{NH}_{3}$ electrosynthesis on a nanostructured iron catalyst at ambient temperature and pressure. The solubility of $\mathrm{N}_{2}$ in $\left[\mathrm{C}_{4} \mathrm{mpyr}\right]$ [eFAP] and $\left[\mathrm{P}_{6,6,6,14}\right][\mathrm{eFAP}]$ is notably higher than that in aqueous solutions. In addition, these ionic liquids can serve as aprotic electrolytes where $\mathrm{H}_{2}$ evolution can be effectively suppressed. Notably, a trace amount of water $\left(20 \times 10^{-6}-250 \times 10^{-6}\right)$ is the only proton source. As a result, an unprecedented current efficiency of $60 \%$ for $\mathrm{NH}_{3}$ synthesis in liquid electrolytes at ambient conditions was achieved.

High current efficiency of ENRR was also realized in a solution of $\mathrm{LiClO}_{4}(0.2 \mathrm{~mol} / \mathrm{L})$ in tetrahydrofuran/ethanol $(99: 1 V / V)$ on metal electrodes [118]. Lithium in the electrolyte acted as a mediator because $\mathrm{Li}^{+}$was reduced on the electrode to deposit metallic $\mathrm{Li}$, which reacted with $\mathrm{N}_{2}$ to form $\mathrm{Li}_{3} \mathrm{~N}$. $\mathrm{Li}_{3} \mathrm{~N}$ underwent a subsequent ethanolysis to generate $\mathrm{NH}_{3}$. Moreover, in this Li-mediated system, the metal electrode can be modified with a functional layer such as superhydrophobic metal-organic framework to suppress the proton availability and accumulate $\mathrm{N}_{2}$ molecules at the electrode surface [119].

Although reducing proton concentration surrounding the catalyst is an effective way to improve the selectivity of ENRR, the sacrifice of current density or $\mathrm{NH}_{3}$ generation rate cannot be overlooked. The operating current density at several microamperes [117, 119] is insufficient. New approaches need to be developed to solve this dilemma.

\section{Summary and Protocols for Electrochemical Ammonia Synthesis}

The past three decades have witnessed a flourishing of interest in electrochemical $\mathrm{NH}_{3}$ synthesis. Table 1 summarizes several representative developments in this realm. For SSAS using $\mathrm{N}_{2}$ and $\mathrm{H}_{2}$ as the reactants, $\mathrm{NH}_{3}$ generation rate could reach the order of $10^{-9} \mathrm{~mol} /\left(\mathrm{cm}^{2} \mathrm{~s}\right)$ to $10^{-8} \mathrm{~mol} /\left(\mathrm{cm}^{2} \mathrm{~s}\right)$, and the current efficiency is considerable. However, either the high temperature [37] (usually larger than $500{ }^{\circ} \mathrm{C}$ ) or the large cell potential [48] limits the energy utilization; furthermore, $\mathrm{H}_{2}$ production is energy consuming and carbon intensive. Molten electrolytes enhance the ionic conductivity and reduce the operating temperature to $200-400{ }^{\circ} \mathrm{C}$. The current efficiency in molten electrolytes is as high as that in SSAS, whereas the $\mathrm{NH}_{3}$ generation rate is faster at the order of $10^{-8}$ $\mathrm{mol} /\left(\mathrm{cm}^{2} \mathrm{~s}\right)$. Notably, reaction from $\mathrm{N}_{2}$ and $\mathrm{H}_{2} \mathrm{O}$ achieves a $\mathrm{NH}_{3}$ production rate of $1.0 \times 10^{-8} \mathrm{~mol} /\left(\mathrm{cm}^{2} \mathrm{~s}\right)$ in molten $\mathrm{NaOH} / \mathrm{KOH}$ at a moderate temperature of $200{ }^{\circ} \mathrm{C}$ [36]. From the perspective of sustainable development, harvesting $\mathrm{NH}_{3}$ from $\mathrm{N}_{2}$ and $\mathrm{H}_{2} \mathrm{O}$ at ambient conditions is the most tempting goal. Nonetheless, this process is extremely challenging because of the competitive hydrogen evolution and difficult

Table 1 Summary of representative developments in electrochemical $\mathrm{NH}_{3}$ synthesis

\begin{tabular}{|c|c|c|c|c|c|c|c|}
\hline Electrolyte type & Reactants & Electrode/catalyst & Conditions $^{\mathrm{a}}$ & $\begin{array}{l}\mathrm{NH}_{3} \text { yield } \\
{\left[\mathrm{mol}^{\prime}\left(\mathrm{cm}^{2} \mathrm{~s}\right)\right]^{\mathrm{b}}}\end{array}$ & $\begin{array}{l}\text { Current effi- } \\
\text { ciency }(\%)\end{array}$ & Applied potential $^{\mathrm{c}}$ & References \\
\hline \multirow[t]{4}{*}{ Solid } & $\mathrm{N}_{2} / \mathrm{H}_{2}$ & Porous Pd & $\mathrm{SrCe}_{0.95} \mathrm{Yb}_{0.05} \mathrm{O}_{3}, 570^{\circ} \mathrm{C}$ & $4.5 \times 10^{-9}$ & 78.00 & N.A. ${ }^{d}$ & [37] \\
\hline & $\mathrm{N}_{2} / \mathrm{H}_{2}$ & $\mathrm{Ag}-\mathrm{Pd}$ & $\begin{array}{l}\mathrm{BaCe}_{0.80} \mathrm{Gd}_{0.10} \mathrm{Sm}_{0.10} \mathrm{O}_{3-\delta}, \\
\quad 6200^{\circ} \mathrm{C}\end{array}$ & $5.82 \times 10^{-9}$ & N.A. & $0.6 \mathrm{~V}$ & [44] \\
\hline & $\mathrm{N}_{2} / \mathrm{H}_{2}$ & $\mathrm{Ag}-\mathrm{Pd}$ & $\mathrm{Ce}_{0.8} \mathrm{Sm}_{0.2} \mathrm{O}_{2-\delta}, 650^{\circ} \mathrm{C}$ & $8.2 \times 10^{-9}$ & N.A. & $0.6 \mathrm{~V}$ & [47] \\
\hline & $\mathrm{N}_{2} / \mathrm{H}_{2}$ & $\mathrm{SmFe}_{0.7} \mathrm{Cu}_{0.3-x} \mathrm{Ni}_{x} \mathrm{O}_{3}$ & Nafion, $80^{\circ} \mathrm{C}$ & $1.13 \times 10^{-8}$ & 90.40 & $2 \mathrm{~V}$ & [48] \\
\hline \multirow[t]{2}{*}{ Molten } & $\mathrm{N}_{2} / \mathrm{H}_{2}$ & Porous Ni & $\begin{array}{l}\text { Molten } \mathrm{LiCl}-\mathrm{KCl}-\mathrm{CsCl} \text { with } \\
0.5 \mathrm{~mol} \% \mathrm{Li}_{3} \mathrm{~N}, 400{ }^{\circ} \mathrm{C}\end{array}$ & $3.33 \times 10^{-8}$ & 72.00 & $0.7 \mathrm{~V}$ versus $\mathrm{Li}^{+} / \mathrm{Li}$ & {$[60]$} \\
\hline & $\mathrm{N}_{2} / \mathrm{H}_{2} \mathrm{O}$ & $\begin{array}{l}\mathrm{Ni} \text { electrode, nano- }-\mathrm{Fe}_{2} \mathrm{O}_{3} \\
\text { catalyst }\end{array}$ & Molten $\mathrm{NaOH} / \mathrm{KOH}, 200^{\circ} \mathrm{C}$ & $1.0 \times 10^{-8}$ & 35.00 & $1.2 \mathrm{~V}$ & [36] \\
\hline \multirow[t]{7}{*}{ Aqueous } & $\mathrm{N}_{2} / \mathrm{H}_{2} \mathrm{O}$ & Au film & $0.1 \mathrm{~mol} / \mathrm{L} \mathrm{KOH}$ & $3.84 \times 10^{-12}$ & 0.12 & $-0.5 \mathrm{~V}$ versus RHE & [81] \\
\hline & $\mathrm{N}_{2} / \mathrm{H}_{2} \mathrm{O}$ & Au nanoclusters & $0.1 \mathrm{~mol} / \mathrm{L} \mathrm{HCl}$ & $1.12 \times 10^{-10}$ & 8.11 & $-0.2 \mathrm{~V}$ versus RHE & [84] \\
\hline & $\mathrm{N}_{2} / \mathrm{H}_{2} \mathrm{O}$ & Pd NP & $0.1 \mathrm{~mol} / \mathrm{L}$ PBS & $1.7 \times 10^{-11}$ & 8.20 & $0.1 \mathrm{~V}$ versus $\mathrm{RHE}$ & [86] \\
\hline & $\mathrm{N}_{2} / \mathrm{H}_{2} \mathrm{O}$ & Bi nanocrystals & $0.5 \mathrm{~mol} / \mathrm{L} \mathrm{K}_{2} \mathrm{SO}_{4}, \mathrm{pH} 3.5$ & $1.44 \times 10^{-8}$ & 66.00 & $-0.6 \mathrm{~V}$ versus $\mathrm{RHE}$ & [87] \\
\hline & $\mathrm{N}_{2} / \mathrm{H}_{2} \mathrm{O}$ & $\mathrm{Bi}_{4} \mathrm{~V}_{2} \mathrm{O}_{11} / \mathrm{CeO}_{2}$ & $0.1 \mathrm{~mol} / \mathrm{L} \mathrm{HCl}$ & $7.6 \times 10^{-10}$ & 10.16 & $-0.2 \mathrm{~V}$ versus RHE & [93] \\
\hline & $\mathrm{N}_{2} / \mathrm{H}_{2} \mathrm{O}$ & $\mathrm{Ru} / \mathrm{MoS}_{2}$ & $0.01 \mathrm{~mol} / \mathrm{L} \mathrm{HCl}, 50^{\circ} \mathrm{C}$ & $1.14 \times 10^{-10}$ & 17.60 & $-0.15 \mathrm{~V}$ versus $\mathrm{RHE}$ & [97] \\
\hline & $\mathrm{N}_{2} / \mathrm{H}_{2} \mathrm{O}$ & VN NP & $0.05 \mathrm{~mol} / \mathrm{L} \mathrm{H}_{2} \mathrm{SO}_{4}$ & $3.3 \times 10^{-10}$ & 6.00 & $-0.1 \mathrm{~V}$ versus RHE & [104] \\
\hline \multirow[t]{2}{*}{ Nonaqueous liquid } & $\mathrm{N}_{2} / \mathrm{H}_{2} \mathrm{O}$ & Nanostructured Fe & {$\left[\mathrm{P}_{6,6,6,14}\right][\mathrm{eFAP}]$} & $2.1 \times 10^{-11}$ & 60.00 & $-0.8 \mathrm{~V}$ versus RHE & [117] \\
\hline & $\mathrm{N}_{2} / \mathrm{H}_{2} \mathrm{O}$ & Ag-Au@ZIF & $\begin{array}{l}\mathrm{LiCF}_{3} \mathrm{SO}_{3}(0.2 \mathrm{~mol} / \mathrm{L}) \text { in THF/ } \\
\quad \text { ethanol }(99: 1 \mathrm{~V} / \mathrm{V})\end{array}$ & $9.5 \times 10^{-12}$ & 18.00 & $2.9 \mathrm{~V}$ & [119] \\
\hline
\end{tabular}

${ }^{a}$ Conditions indicate electrolyte, temperature, and pressure. Unless otherwise specified, the experiments were conducted under RT and ambient pressure

${ }^{b}$ From given or calculated data based on reference data in the literature. Normalized based on the geometric areas of the electrodes

${ }^{\mathrm{c}}$ The potentials without a reference refer to the cell potentials

${ }^{\mathrm{d}}$ N.A. stands for not applicable 
$\mathrm{N}_{2}$ activation. The $\mathrm{NH}_{3}$ yield in aqueous electrolytes ranges from the order of $10^{-12} \mathrm{~mol} /\left(\mathrm{cm}^{2} \mathrm{~s}\right)$ to $10^{-10} \mathrm{~mol} /\left(\mathrm{cm}^{2} \mathrm{~s}\right)$ with a current efficiency less than $10 \%$. Reducing the proton availability, such as by using aprotic solvents, is an approach to notably boost the current efficiency; however, the operating current density is extremely small, leading to a low $\mathrm{NH}_{3}$ yield $[117,119]$. One $\mathrm{Bi}$ nanocrystal catalyst in aqueous media achieves a high $\mathrm{NH}_{3}$ yield of $1.44 \times 10^{-8} \mathrm{~mol} /\left(\mathrm{cm}^{2}\right.$ s) and a high current efficiency of $60 \%$ [87]. This result is exciting, but more study is needed to solve the problems of high overpotential and the narrow operating potential window.

In spite of the reported progress thus far, electrochemical $\mathrm{NH}_{3}$ production will need to achieve considerable progress toward practical applications that require a minimum $\mathrm{NH}_{3}$ production rate in the order of $10^{-7} \mathrm{~mol} /\left(\mathrm{cm}^{2} \mathrm{~s}\right)$ [13]. More importantly, electrochemical $\mathrm{NH}_{3}$ production needs both scientific and engineering design to make the process less energy consuming than the well-developed $\mathrm{H}-\mathrm{B}$ process.

Another challenge is that the slow $\mathrm{NH}_{3}$ generation rate of ENRR causes difficulty in attributing the detected $\mathrm{NH}_{3}$ to real electrochemical $\mathrm{N}_{2}$ fixation given the existence of numerous exogenous nitrogen contaminants. In addition, $\mathrm{N}_{2}$ as a robust and nonpolar molecule is extremely difficult to fix under ambient conditions. Although ENRR has achieved great enhancement in ammonia production rates in the past 4 years, limited papers provide rigorous evidence to prove that ammonia truly comes from $\mathrm{N}_{2}$. In any given experiment, adventitious ammonia can be introduced in the reaction system in various ways, as illustrated by a rigorous protocol by Andersen et al. [120]. Ammonia contamination could be present in air, atmosphere, human breath or Nafion membranes or originate from nitrogen-containing compounds that are normally present in the nitrogen gas supply. Numerous electrocatalysts are also nitrogen-containing compounds or fabricated from nitrogen-containing precursors. Therefore, excluding the interference of exogenous contamination and confirming the source of fixed nitrogen are the prerequisites to reporting a positive result. Fortunately, benchmarking protocols are being progressively established to identify and eliminate contamination sources [40, $73,120]$, to prevent false positives and standardize ENRR experiments. Upon successful detection of ammonia after running electrolysis, one must conduct control experiments with Ar gas supply under the exact same conditions and with $\mathrm{N}_{2}$ gas in the open-circuit condition. Isotope labeling using ${ }^{15} \mathrm{~N}_{2}$ is a necessary confirmation procedure. Numerous papers reported the qualitative detection of ${ }^{15} \mathrm{NH}_{3}$ or ${ }^{15} \mathrm{NH}_{4}{ }^{+}$from ${ }^{15} \mathrm{~N}_{2}$, thereby alleging the successful fixing of $\mathrm{N}_{2}$. However, ${ }^{15} \mathrm{~N}_{2}$ gas stock normally contains ${ }^{15} \mathrm{~N}$-labeled nitrate or ammonia, which invalidates the detected results [121]. Therefore, gas-cleaning unit must be applied before bubbling $\mathrm{N}_{2}$ stream to the electrolyte. Meanwhile, the yield of ${ }^{15} \mathrm{NH}_{3}$ should be quantitatively consistent with that of ${ }^{14} \mathrm{NH}_{3}$ during identical reduction experiments. Andersen's work demonstrates excellently how to perform quantitative isotope measurements. A copper catalyst trap was used to eliminate $\mathrm{N}$-containing contaminations, and a gas circulation system was used to maximize the use of expensive ${ }^{15} \mathrm{~N}_{2}$ gas [120]. The developing rigorous protocols will enable the identification of ENRR results by preventing false positive data and contribute to the development of more efficient processes toward electrochemical $\mathrm{NH}_{3}$ production.

\section{Photocatalytic Ammonia Synthesis}

Effectively capturing solar energy for the production of fertilizers and fuels is an ambitious and challenging goal [122]. Green ammonia from nitrogen photofixation has drawn increasing attention in recent years [19, 123]. Abiotic photofixation of dinitrogen in soils and sands has been suggested to be the third most significant source of natural nitrogen fixation, apart from biological $\mathrm{N}_{2}$ fixation and lightning discharges [23, 124]. The investigation of solar-driven $\mathrm{N}_{2}$ fixation is significant for people to comprehend and modulate the nitrogen cycle. Although early studies mainly focused on titania-based catalysts, a sharp increase occurred in recent years regarding photocatalytic $\mathrm{N}_{2}$ fixation on emerging catalytic systems.

\section{Ammonia Synthesis on Powdered Photocatalysts}

\section{Titania-Based Photocatalysts}

Rutile $\mathrm{TiO}_{2}$ in sands or soils is considered to be the $\mathrm{N}_{2}$ reduction catalyst in the presence of light and water [124]. The first experiment on $\mathrm{N}_{2}$ photoreduction with water splitting was reported by Schrauzer and Guth [125] on outgassed rutile $\mathrm{TiO}_{2}$ powders. $\mathrm{H}_{2}$ evolution was notably inhibited in $\mathrm{N}_{2}$ atmosphere, whereas iron doping enhanced the photocatalytic reactivity. Since then, titania has been intensively explored as the photocatalyst for $\mathrm{N}_{2}$ fixation, although other metal oxide semiconductors, such as tungsten oxide [126] and iron oxide [127], were also investigated. Ranjit et al. [128] studied photocatalytic reduction of $\mathrm{N}_{2}$ to $\mathrm{NH}_{3}$ on noble-metal-loaded $\mathrm{TiO}_{2}$. They observed a correlation between $\mathrm{NH}_{3}$ yield and the $\mathrm{M}-\mathrm{H}$ bond strength, where a high-bond strength gives rise to a high $\mathrm{NH}_{3}$ yield. Hoshino et al. [129] reported $\mathrm{N}_{2}$ photoreduction on needle-like solid ammonium perchlorate $\left(\mathrm{NH}_{4} \mathrm{ClO}_{4}\right)$ using a $\mathrm{TiO}_{2}$ /conducting polymer (poly 3-methylthiophene, P3MeT) catalyst. Under illumination, photogenerated carriers at the $\mathrm{TiO}_{2} / \mathrm{P} 3 \mathrm{MeT}$ interface contributed to $\mathrm{NH}_{3}$ synthesis in the presence of water. Meanwhile, $\mathrm{ClO}_{4}{ }^{-}$was doped from $\mathrm{P} 3 \mathrm{MeT}$ driven by electrons, and the acid-base reaction formed mesoscale 
$\mathrm{NH}_{4} \mathrm{ClO}_{4}$ needles. Kisch and colleagues [130] reported nitrogen fixation at nanostructured iron titanate films, where the highest $\mathrm{NH}_{3}$ generation rate was realized on iron titanate film with Fe:Ti ratio of 1:1. Zhao et al. [131] fabricated Fe-doped $\mathrm{TiO}_{2}$ NPs with highly exposed (101) facets by a two-step hydrothermal method. Optimal doping of $\mathrm{Fe}^{3+}$ is essential to the improvement of photocatalytic activity.

Recently, the introduction of $\mathrm{O}_{\text {vac }}$ has drawn new insight into $\mathrm{N}_{2}$ photofixation on $\mathrm{TiO}_{2}$ catalysts. Hirakawa et al. [132] introduced a large number of $\mathrm{O}_{\text {vac }}$ in a commercially available $\mathrm{TiO}_{2}$ by $\mathrm{H}_{2}$ treatment. Under UV light illumination, $\mathrm{N}_{2}$ molecules were reduced to $\mathrm{NH}_{3}$ by $\mathrm{Ti}^{3+}$ species on $\mathrm{O}_{\text {vac }}$ (Fig. 11a), leading to a solar-to-chemical energy conversion efficiency of $0.02 \%$. However, methods such as $\mathrm{H}_{2}$ reduction do not avoid the introduction of $\mathrm{O}_{\text {vac }}$ to the bulk to form bulk defects, which potentially act as carrier traps and induce charge recombination [133]. Therefore, the introduction of $\mathrm{O}_{\text {vac }}$ on the outermost surface is highly desirable for $\mathrm{TiO}_{2}$ and many other reducible oxides. Gong and coworkers [39] reported the conversion of $\mathrm{N}_{2}$ to $\mathrm{NH}_{3}$ in pure water using a plasmon-enhanced rutile $\mathrm{TiO}_{2} \mathrm{NR}$ array modified with surface $\mathrm{O}_{\text {vac }}$, which were created by atomic layer deposition (ALD). This method ensures the introduction of $\mathrm{O}_{\text {vac }}$ on the surface without affecting bulk structure. Compared with the less active rutile $\mathrm{TiO}_{2}$ surface, the amorphous ALD $\mathrm{TiO}_{2}$ layer $\left(\mathrm{a}-\mathrm{TiO}_{2}\right)$ with catalytic centers of surface $\mathrm{O}_{\text {vac }}$ could promote $\mathrm{N}_{2}$ adsorption and activation, greatly enhancing the $\mathrm{N}_{2}$ photofixation rate. Meanwhile, surface plasmons of $\mathrm{Au}$ extended the absorption range of $\mathrm{TiO}_{2}$ to the visible region and provided high-energy hot electrons for $\mathrm{N}_{2}$ reduction (Fig. 11b). Accordingly, the $\mathrm{TiO}_{2} / \mathrm{Au} / \mathrm{a}-\mathrm{TiO}_{2}$ photoelectrode exhibited a notably higher $\mathrm{NH}_{3}$ production rate than bare $\mathrm{TiO}_{2}$, achieving $13.4 \mathrm{nmol} /\left(\mathrm{cm}^{2} \mathrm{~h}\right)$ under 1 sun illumination [39]. Similarly, Yang et al. [134] illustrated a "working-in-tandem" nitrogen photofixation system, which was realized by assembling plasmonic Au nanocrystals on $\mathrm{O}_{\text {vac }}$-rich ultrathin $\mathrm{TiO}_{2}$ nanosheets (Fig. 11c, d). The $\mathrm{O}_{\text {vac }}$ on the $\mathrm{TiO}_{2}$ nanosheets chemisorbed and activated $\mathrm{N}_{2}$ molecules, which were further reduced to ammonia by hot electrons generated from plasmonic gold nanocrystals. The apparent quantum efficiency for the conversion of incident photons to $\mathrm{NH}_{3}$ reached $0.82 \%$ at $550 \mathrm{~nm}$. The $\mathrm{N}_{2}$ photofixation rate can be further improved by optimizing the absorption of visible light with the mixture of Au nanospheres and NRs.

\section{D-Layered Photocatalysts}

Layered bismuth oxyhalides for nitrogen photofixation were first reported by Zhang and coworkers [31, 135]. Under visible-light illumination and ambient conditions, efficient $\mathrm{NH}_{3}$ was generated from $\mathrm{N}_{2}$ and water on bismuth oxybromide $(\mathrm{BiOBr})$ nanosheets of $\mathrm{O}_{\mathrm{vac}}$ in the absence of any organic scavengers and precious-metal cocatalysts. $\mathrm{O}_{\text {vac }}$ on the
Fig. 11 Solar $\mathrm{N}_{2}$ fixation on $\mathrm{TiO}_{2}$ photocatalysts. a Proposed photocatalytic cycle for $\mathrm{N}_{2}$ fixation on the $\mathrm{Ti}^{3+}$ sites of rutile $\mathrm{TiO}_{2}$ (110) surface. Reproduced with permission from Ref. [97]. Copyright 2017, American Chemical Society. b Illustration of the synergistic effect of surface $\mathrm{O}_{\text {vac }}$ and plasmonic Au NPs for photocatalytic $\mathrm{N}_{2}$ reduction on $\mathrm{TiO}_{2} / \mathrm{Au} / \mathrm{a}-\mathrm{TiO}_{2}$. Reproduced with permission from Ref. [39]. Copyright 2018, Wiley-VCH. c Transmission electron microscopy (TEM) image of $\mathrm{Au} / \mathrm{TiO}_{2}$ -

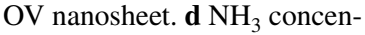
tration on the four catalysts as a function of time. Reproduced with permission from Ref. [134]. Copyright 2018, American Chemical Society
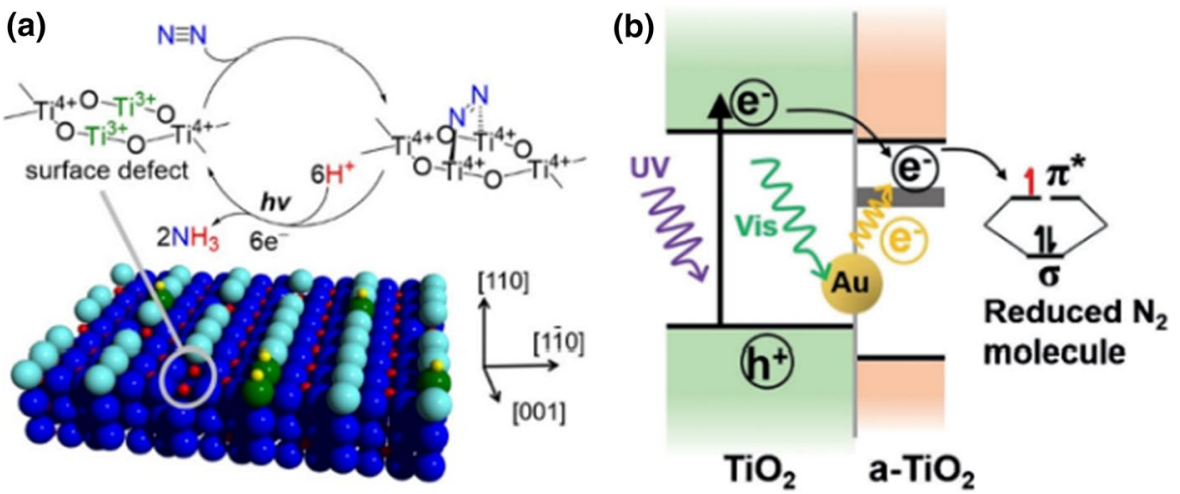

(c)

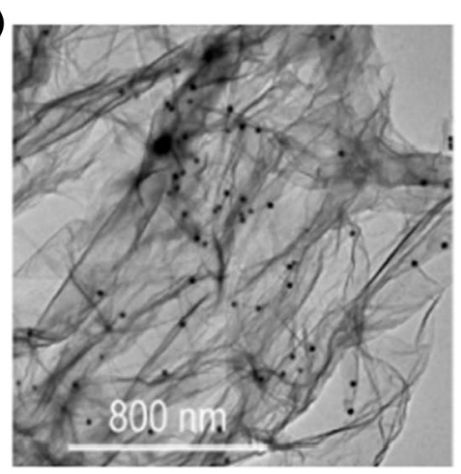

(d)

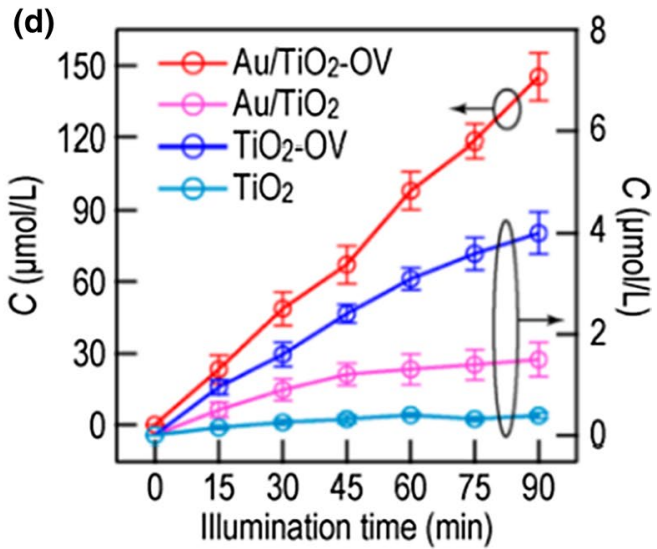


exposed (001) facets provided localized electrons for $\pi$-backdonation and activated adsorbed $\mathrm{N}_{2}$, which could be reduced to $\mathrm{NH}_{3}$ by the transferred electrons from the conduction band of excited BiOBr nanosheets (Fig. 12a). The resultant $\mathrm{N}_{2}$ photofixation rate on $\mathrm{BiOBr}$ was $104.2 \mu \mathrm{mol} /(\mathrm{h} \mathrm{g})$ [135]. Zhang and coworkers [136] further demonstrated that $\mathrm{O}_{\text {vac }}$ on $\mathrm{BiOCl}$ could act as the catalytic centers and contribute to the solar light driven $\mathrm{N} \equiv \mathrm{N}$ triple-bond cleavage via a proton-assisted electron-transfer pathway. In addition, different $\mathrm{BiOCl}$ facets strongly influence the $\mathrm{N}_{2}$ reduction pathways by affecting both the adsorption structure and the activation level of $\mathrm{N}_{2}$.

Graphitic carbon nitride $\left(\mathrm{g}-\mathrm{C}_{3} \mathrm{~N}_{4}\right)$ is a burgeoning material for $\mathrm{N}_{2}$ photofixation, either as a catalytic or a supportive material [137-143]. Dong et al. [137] observed that $\mathrm{N}_{\mathrm{vac}}$ endowed $\mathrm{g}_{-} \mathrm{C}_{3} \mathrm{~N}_{4}$ with the photocatalytic $\mathrm{N}_{2}$ fixation capability because $\mathrm{N}_{\mathrm{vac}}$ could selectively adsorb and activate $\mathrm{N}_{2}$ given their same shape and size with the nitrogen atom in $\mathrm{N}_{2}$. Cao et al. [138] reported a Z-scheme heterojunction-structured photocatalyst: 3,4-dihydroxybenzaldehyde-functionalized $\mathrm{Ga}_{2} \mathrm{O}_{3}$ /graphitic carbon nitride $\left(\mathrm{Ga}_{2} \mathrm{O}_{3}-\mathrm{DBD} / \mathrm{g}-\mathrm{C}_{3} \mathrm{~N}_{4}\right)$. The interaction between aromatic aldehydes in $\mathrm{Ga}_{2} \mathrm{O}_{3}$-DBD and the terminal $-\mathrm{NH}_{2}$ groups in $\mathrm{g}^{-} \mathrm{C}_{3} \mathrm{~N}_{4}$ improved the dispersion of $\mathrm{Ga}_{2} \mathrm{O}_{3}$-DBD NPs and resulted in the formation of a well-combined interface, which enhanced the charge transfer rates. Aromatic rings with good conductivity acted as electron mediators and promoted the recombination between photogenerated electrons from the conduction band of $\mathrm{Ga}_{2} \mathrm{O}_{3}$ and photogenerated holes from the valence band of $\mathrm{g}-\mathrm{C}_{3} \mathrm{~N}_{4}$, boosting the overall photovoltage [138]. Hu et al. [139, 140] anchored $\mathrm{Fe}^{3+}$ and $\mathrm{Cu}^{1+}$ at the interstitial position of $\mathrm{g}-\mathrm{C}_{3} \mathrm{~N}_{4}$, where coordinative $\mathrm{M}-\mathrm{N}$ bonds were formed. The metaldoped $\mathrm{g}-\mathrm{C}_{3} \mathrm{~N}_{4}$ exhibited notably higher photoactivity for $\mathrm{N}_{2}$ reduction compared with bare $\mathrm{g}-\mathrm{C}_{3} \mathrm{~N}_{4}$. DFT simulations showed that a high nitrogen adsorption energy was obtained on anchored metal sites, and $\mathrm{N}-\mathrm{N}$ bond could be elongated. DOS results indicate that the electrons of $\sigma_{g} 2 p$ orbital (highest-occupied molecular orbital) in nitrogen atom were substantially delocalized when $\mathrm{N}_{2}$ adsorbed on metal-doped sites, and the orbital energy almost crossed that of $\pi_{g} * 2 p$ orbital (LUMO), illustrating that $\mathrm{Fe}^{3+}$ or $\mathrm{Cu}^{1+}$ sites can activate the $\mathrm{N}_{2}$ molecule effectively. Jiang and colleagues [142] designed and fabricated a new $\mathrm{TiO}_{2} @ \mathrm{C} / \mathrm{g}-\mathrm{C}_{3} \mathrm{~N}_{4}$ photocatalyst through thermal treatment of a mixture of melamine and MXene $\mathrm{Ti}_{3} \mathrm{C}_{2} \mathrm{~T}_{x}$. This method endowed carbon nanosheetsupported $\mathrm{TiO}_{2}$ with abundant $\mathrm{Ti}^{3+}$ species that were tightly wrapped by in situ-formed $\mathrm{g}_{-} \mathrm{C}_{3} \mathrm{~N}_{4}$ nanosheets. This heterojunction enhanced light absorption and charge separation, where electrons were injected from $\mathrm{g}_{-} \mathrm{C}_{3} \mathrm{~N}_{4}$ to $\mathrm{Ti}^{3+}$ on $\mathrm{TiO}_{2}$ for $\mathrm{N}_{2}$ activation and reduction (Fig. 12b).

Graphene could generate a high density of hot electrons well above the Fermi level under visible light [144, 145]. Chen and colleagues [146] noted that light-generated highly energetic hot/free electrons of graphene could act as a promising reducing agent for $\mathrm{NH}_{3}$ synthesis from $\mathrm{N}_{2}$ and $\mathrm{H}_{2}$ under ambient conditions. They fabricated an iron- and
Fig. 12 Solar $\mathrm{N}_{2}$ fixation on $2 \mathrm{D}$ photocatalysts. a Schematic of $\mathrm{N}_{2}$ reduction on $\mathrm{O}_{\text {vac }}$ of excited $\mathrm{BiOBr}$ nanosheets. Reproduced with permission from Ref. [135]. Copyright 2015, American Chemical Society. b Schematic of the energy band structure and electron-hole separation of $\mathrm{TiO}_{2} @ \mathrm{C} / \mathrm{g}-\mathrm{C}_{3} \mathrm{~N}_{4}$ Adapted with permission from Ref. [142]. Copyright 2018, the Royal Society of Chemistry. c Proposed pathway for the $\mathrm{NH}_{3}$ synthesis using Fe@3DG catalyst under light illumination. Adapted with permission from Ref. [146]. Copyright 2016, American Chemical Society (a)

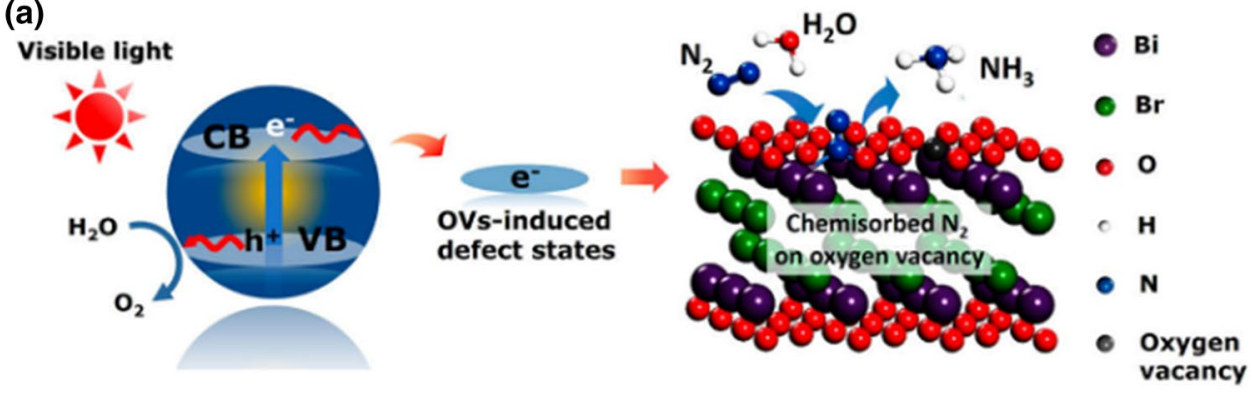

(b)

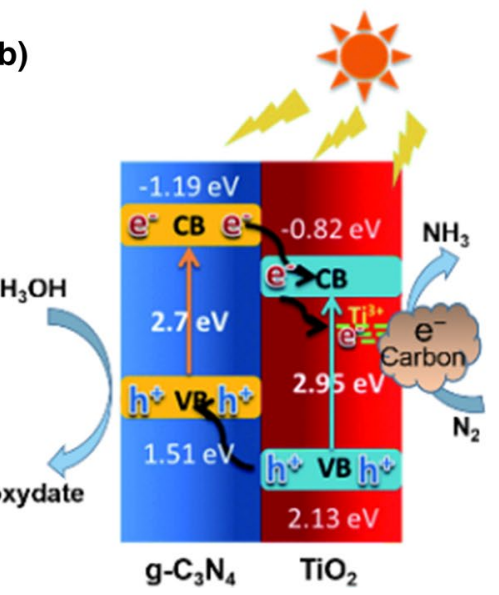

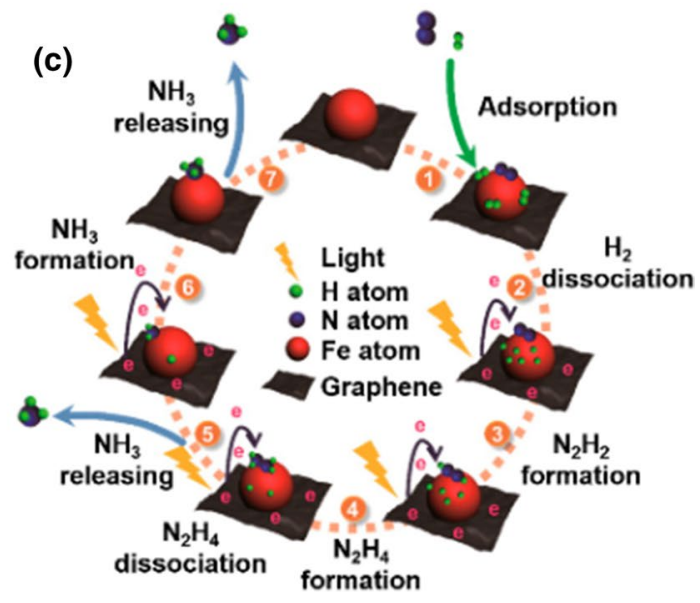


graphene-based catalyst, Fe@3DGraphene, for $\mathrm{NH}_{3}$ photosynthesis. Hot electrons from graphene induced by visible light were ejected onto the Fe catalytic sites, where $\mathrm{N}_{2}$ activation and $\mathrm{NH}_{3} / \mathrm{H}_{2}$ generation occurred directly, without any other agents (Fig. 12c). Alumina as a structural promoter enhanced the stability of Fe@3DGraphene up to $50 \mathrm{~h}$ [146]. The same group further proved that nano- $\mathrm{Al}_{2} \mathrm{O}_{3}$ acting as a barrier among nano- $\mathrm{Fe}_{2} \mathrm{O}_{3}$ could significantly prevent the aggregation of $\mathrm{Fe}_{2} \mathrm{O}_{3}$ particles, improving the stability of catalysts [147].

A series of ultrathin layered-double-hydroxide (LDH) nanosheet photocatalysts of the type $\mathrm{M}^{\mathrm{II}} \mathrm{M}^{\mathrm{III}}-\mathrm{LDH}$ (where $\mathrm{M}^{\mathrm{II}}=\mathrm{Mg}, \mathrm{Zn}, \mathrm{Ni}, \mathrm{Cu}$; and $\mathrm{M}^{\mathrm{III}}=\mathrm{Al}, \mathrm{Cr}$ ) were synthesized by simple coprecipitation routes [148]. These LDH nanosheets were engineered with $\mathrm{O}_{\text {vac }}$ defects to enhance the absorption and activation of $\mathrm{N}_{2}$. Especially, the CuCr-LDH photocatalyst exhibited a high activity under visible light for the photoreduction of $\mathrm{N}_{2}$ to $\mathrm{NH}_{3} \cdot \mathrm{Cu}^{2+}$ ions in the $\mathrm{LDH}$ nanosheets were assumed to introduce additional structural distortions and compressive strain, which boosted the interaction between the nanosheets and $\mathrm{N}_{2}$ and thereby enhanced $\mathrm{NH}_{3}$ formation.

\section{Other Semiconductor Photocatalysts}

Bismuth oxyhalide is susceptible to photocorrosion, where surface $\mathrm{O}_{\text {vac }}$ is easily oxidized to lose the catalytic sites. Wang et al. [149] resolved this problem using self-assembled $5 \mathrm{~nm}$ diameter $\mathrm{Bi}_{5} \mathrm{O}_{7} \mathrm{Br}$ nanotubes (NTs) through a low-temperature wet chemical method. The $\mathrm{Bi}_{5} \mathrm{O}_{7} \mathrm{Br}$ NTs contained abundant and light-switchable $\mathrm{O}_{\text {vac }}$, realizing excellent and stable photosynthesis of $\mathrm{NH}_{3}$ in pure water. The $\mathrm{NH}_{3}$ generation rate was as high as $1.38 \mathrm{mmol} /(\mathrm{h} \mathrm{g})$, with an apparent quantum efficiency of $2.3 \%$ at $420 \mathrm{~nm}$.

Bismuth monoxide ( $\mathrm{BiO})$ quantum dot is a low-valence metal oxide semiconductor that has fewer coordination atoms than its high-valence states [150]. This condition endows $\mathrm{BiO}$ with high electron-donating power and empty $6 d$ orbitals for $\mathrm{N}_{2}$ adsorption and activation. The $\mathrm{N}_{2}$ molecule could be stretched and activated by alternately arranged Bi atoms by donating electrons to the empty $\mathrm{Bi} 6 d$ orbitals. Without hole scavengers, $\mathrm{BiO}$ quantum dots exhibited a high $\mathrm{NH}_{3}$ generation rate of $1226 \mu \mathrm{mol} /(\mathrm{h} \mathrm{g})$.

\section{Biohybrid and Biomimetic Photocatalysts}

In a bioinorganic system, cadmium sulfide (CdS) nanocrystals were used to photosensitize the nitrogenases molybdenum-iron (MoFe) protein, where light harvesting from CdS replaced ATP hydrolysis on the Fe protein to transfer electrons for enzymatic reduction of $\mathrm{N}_{2}$ into $\mathrm{NH}_{3}$ [7]. This CdS:MoFe protein biohybrid system achieved an optimal turnover rate of 75 per minute, which is $63 \%$ of the ATP-coupled reaction for nitrogenase. Kanatzidis and coworkers [151] reported a nitrogenase-inspired biomimetic chalcogel system that exhibited photoactivity for $\mathrm{N}_{2}$ reduction to $\mathrm{NH}_{3}$ in aqueous media under ambient pressure and RT. The high-surface-area amorphous chalcogels were composed of $\mathrm{Mo}_{2} \mathrm{Fe}_{6} \mathrm{~S}_{8}(\mathrm{SPh})_{3}$ or $\mathrm{Fe}_{4} \mathrm{~S}_{4}$ with $\mathrm{Sn}_{2} \mathrm{~S}_{6}$ clusters and exhibited strong optical absorption. Compared with chalcogels with $\mathrm{Mo}_{2} \mathrm{Fe}_{6} \mathrm{~S}_{8}(\mathrm{SPh})_{3}$ cluster [151], Mo-free chalcogels containing only $\mathrm{Fe}_{4} \mathrm{~S}_{4}$ clusters are more efficient for $\mathrm{N}_{2}$ reduction to $\mathrm{NH}_{3}$ [152]. This result suggests that $\mathrm{Fe}$ might be the active site for $\mathrm{N}_{2}$ binding, similar to that in nitrogenase.

\section{Ammonia Synthesis on Photoelectrodes}

Unlike photoelectrochemical (PEC) water splitting [153, 154] or $\mathrm{CO}_{2}$ reduction [155], $\mathrm{N}_{2}$ fixation in PEC systems was rarely investigated. Limited studies reported $\mathrm{N}_{2}$ photofixation on photoelectrodes [39, 156-162].

The first trial was realized in a PEC cell that contained a $\mathrm{p}-\mathrm{GaP}$ cathode and an $\mathrm{Al}$ metal anode immersed in a nonaqueous electrolyte. $\mathrm{N}_{2}$ was reduced to $\mathrm{NH}_{3}$ on illuminated p-GaP electrode, whereas $\mathrm{Al}$ was continually consumed as the reducing agent [156]. Hamers and coworkers [157] used diamond as a solid-state source of solvated electrons for $\mathrm{N}_{2}$ reduction. The conduction band edge of diamond lay at about $1 \mathrm{eV}$ above the vacuum level, which enabled the electrons to be directly ejected into the inert $\mathrm{N}_{2}$ molecules with negligible barrier (Fig. 13a). Oshikiri et al. [158, 160] investigated Au-decorated $\mathrm{SrTiO}_{3}$ photoelectrode with $\mathrm{Ru}$ or $\mathrm{Zr} / \mathrm{ZrO}_{x}$ as the cocatalysts. Water was oxidized by holes on the Au side, whereas excited hot electrons were conducted through the conduction band of $\mathrm{SrTiO}_{3}$ to the catalyst side for $\mathrm{N}_{2}$ reduction (Fig. 13b). MacFarlane and colleagues [159] presented a solar-driven PEC cell based on plasmonenhanced black silicon nanowires (NWs) for the reduction of $\mathrm{N}_{2}$ to ammonia. When sulfite was used as a reactant, the process could produce ammonium sulfate, an important fertilizer with high economic value (Fig. 13c). Li et al. [161] fabricated GaN NW array on a silicon substrate by plasmaassisted molecular beam epitaxy. Afterward, finely dispersed sub-nanoclusters of Ru were deposited on $\mathrm{GaN}$ with a high load of $5 \mathrm{wt} \%$ (Fig. 13d), forming a Schottky barrier junction between Ru and GaN (Fig. 13e), which resulted in partially negatively charged $\mathrm{Ru}$ species for elevated $\mathrm{N}_{2}$ reduction performance under illumination. Zheng et al. [162] designed an aerophilic-hydrophilic heterostructured Si-based composite photocathode for PEC reduction of $\mathrm{N}_{2}$ to $\mathrm{NH}_{3}$. Polytetrafluoroethylene (PTFE) porous framework was used as the $\mathrm{N}_{2}$ diffusion layer, whereas Au NPs acted as the active sites and the electric contact between PTFE framework and Si. This structure formed an aerophilic-hydrophilic functional layer, which enriched $\mathrm{N}_{2}$ concentration at the Au active sites and suppressed HER by reducing proton availability. This 

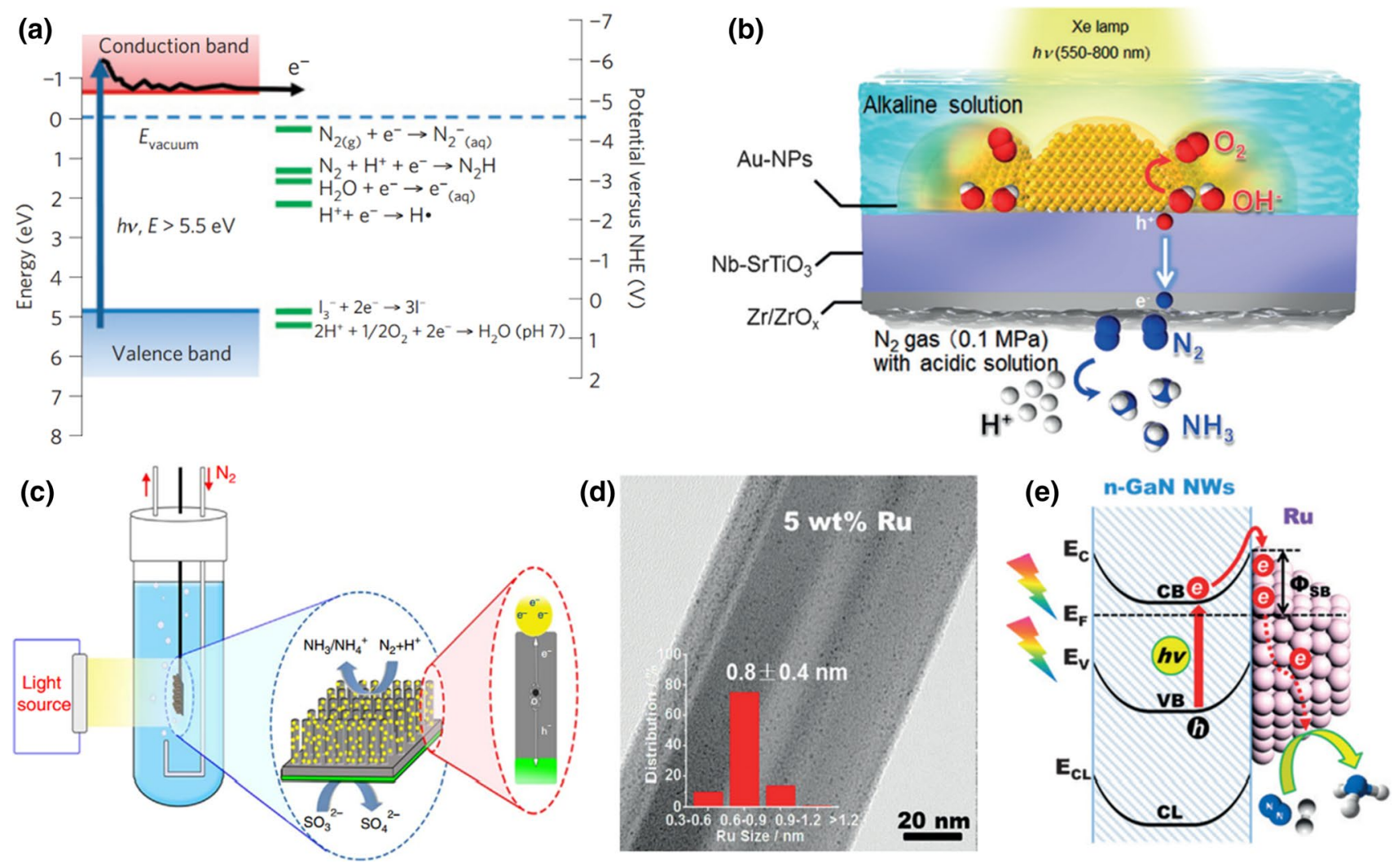

Fig. 13 Solar nitrogen fixation on photoelectrodes. a Energy-level diagram of diamond. Reproduced with permission from Ref. [157]. Copyright 2013, Macmillan Publishers Limited. b Scheme of PEC $\mathrm{N}_{2}$ reduction cell composed of $\mathrm{Nb}-\mathrm{SrTiO}_{3}$ photoelectrode loaded with $\mathrm{Au}$ NPs and a $\mathrm{Zr} / \mathrm{ZrO}_{x}$ catalytic layer. Reproduced with permission from Ref. [160]. Copyright 2016, Wiley-VCH. c Schematic of PEC

photocathode exhibited an $\mathrm{NH}_{3}$ yield rate of $3.1 \times 10^{-10} \mathrm{~mol} /$ $\left(\mathrm{cm}^{2} \mathrm{~s}\right)$ and a current efficiency of $37.8 \%$ at $-0.2 \mathrm{~V}_{\mathrm{RHE}}$ at ambient condition.

\section{Summary for Photocatalytic Ammonia Synthesis}

Table 2 lists the important developments in photocatalytic $\mathrm{NH}_{3}$ synthesis. In photocatalyst systems, the $\mathrm{NH}_{3}$ yield has enhanced from the order of $\mu \mathrm{mol} /(\mathrm{h} \mathrm{g})$ to $\mathrm{mmol} /(\mathrm{h} \mathrm{g})$. This increase is a notable improvement, but the production rate is only realized at the laboratory scale and still cannot meet the requirements for practical use. In PEC systems, the $\mathrm{NH}_{3}$ yield is evidently smaller than that in ENRR at present. In addition to the low yields, several other issues need to be addressed for photocatalytic $\mathrm{NH}_{3}$ synthesis. First, many photocatalytic systems require an electron-donating scavenger to consume photogenerated holes, which would otherwise oxidize $\mathrm{H}_{2} \mathrm{O}$ to $\mathrm{O}_{2}$ (kinetically unfavorable) or oxidize the generated $\mathrm{NH}_{3}$ to $\mathrm{NO}_{x}$ (decrease $\mathrm{NH}_{3}$ production). However, the hole scavenger itself (e.g., alcohols) often comes from fossil fuels and
$\mathrm{N}_{2}$ reduction cell with Au-decorated black silicon NW array. Reproduced with permission from Ref. [159]. Copyright 2016, Macmillan Publishers Limited. d TEM image of $5 \mathrm{wt} \%$ Ru-modified GaN NW. e Schematic for the formation of the Schottky barrier between $n$-type GaN NWs and metallic Ru clusters. d, e Reproduced with permission from Ref. [161]. Copyright 2017, Wiley-VCH

would increase costs. Second, most papers reported did not specify the light intensity, which is one of the most important parameters in photocatalytic reactions. Therefore, comparison of different works or evaluation of the energy conversion efficiency is difficult. Third, standards and protocols must be established to confirm that $\mathrm{NH}_{3}$ is derived from $\mathrm{N}_{2}$, similar to the procedures in ENRR. The residual contaminations in photocatalysts, which are dispersed in the solution, are more likely to be released than those on electrodes, which might lead to false positive results.

Despite the persistent interest and significance of photocatalytic $\mathrm{NH}_{3}$ synthesis, little advancement has been made in comprehending the fundamental mechanisms in the reaction. The band gap must be systematically tuned for effective absorption of sunlight and high photoactivity for solar-to-ammonia conversion. Moreover, advanced in situ or operando characterization techniques are indispensable. For instance, in situ Fourier transform infrared spectroscopy (FTIR) helps in examining the adsorbed nitrogen intermediates on photocatalyst surfaces. Photocorrosion under 
Table 2 Summary of representative developments in photocatalytic $\mathrm{NH}_{3}$ synthesis

\begin{tabular}{|c|c|c|c|c|c|}
\hline & Catalyst/electrode & Light source $^{\mathrm{a}}$ & Hole scavenger & $\mathrm{NH}_{3}$ yield $^{\mathrm{b}}$ & References \\
\hline \multirow[t]{10}{*}{ Photocatalyst } & $0.24 \mathrm{wt} \% \mathrm{Ru} / \mathrm{TiO}_{2}$ & Xe lamp & Ethanol & $29.4 \mu \mathrm{mol} /(\mathrm{h} \mathrm{g})$ & [128] \\
\hline & JRC-TIO-6 (rutile) & $\operatorname{Hg}$ lamp $(\lambda>280 \mathrm{~nm})$ & 2-PrOH & $0.73 \mu \mathrm{mol} /(\mathrm{h} \mathrm{g})$ & [132] \\
\hline & $\mathrm{Au} / \mathrm{TiO}_{2}$ nanosheet & Xe lamp $(\lambda>420 \mathrm{~nm})$ & Methanol & $74.7 \mu \mathrm{mol} /(\mathrm{h} \mathrm{g})$ & [134] \\
\hline & $\mathrm{BiOBr}$ nanosheet & Xe lamp $(\lambda>420 \mathrm{~nm})$ & None & $104.2 \mu \mathrm{mol} /(\mathrm{h} \mathrm{g})$ & [135] \\
\hline & $\mathrm{TiO}_{2} @ \mathrm{C} / \mathrm{g}-\mathrm{C}_{3} \mathrm{~N}_{4}$ & Xe lamp $(\lambda>420 \mathrm{~nm})$ & Methanol & $250.6 \mu \mathrm{mol} /(\mathrm{h} \mathrm{g})$ & [142] \\
\hline & $\mathrm{Cu}-\mathrm{Cr} \mathrm{LDH}$ & Xe lamp & None & $73.9 \mu \mathrm{mol} /(\mathrm{h} \mathrm{g})$ & [148] \\
\hline & Fe-Al@3DGraphene & $\mathrm{Hg}$ lamp & None & $25.3 \mu \mathrm{mol} /(\mathrm{h} \mathrm{g})$ & {$[147]$} \\
\hline & $\mathrm{Bi}_{5} \mathrm{O}_{7} \mathrm{Br} \mathrm{NT}$ & Xe lamp $(\lambda>400 \mathrm{~nm})$ & None & $1380 \mu \mathrm{mol} /(\mathrm{h} \mathrm{g})$ & [149] \\
\hline & $\mathrm{BiO}$ quantum dots & Xe lamp & None & $1226 \mu \mathrm{mol} /(\mathrm{h} \mathrm{g})$ & {$[150]$} \\
\hline & FeMoS chalcogel & Xe lamp, $100 \mathrm{~mW} / \mathrm{cm}^{2}$ & Sodium ascorbate & $91.6 \mu \mathrm{mol} /(\mathrm{h} \mathrm{g})$ & [151] \\
\hline \multirow[t]{3}{*}{ Photoelectrode } & $\mathrm{Au} / \mathrm{Nb}-\mathrm{SrTiO}_{3} / \mathrm{Zr} / \mathrm{ZrO}_{x}$ & Xe lamp, $550-800 \mathrm{~nm}$ & ethanol & $1.8 \times 10^{-12} \mathrm{~mol} /\left(\mathrm{cm}^{2} \mathrm{~s}\right)^{\mathrm{c}}$ & {$[160]$} \\
\hline & $\mathrm{Cr} / \mathrm{black}-\mathrm{Si} / \mathrm{Au}$ & Xe lamp, $200 \mathrm{~mW} / \mathrm{cm}^{2}$ & $\mathrm{Na}_{2} \mathrm{SO}_{3}$ & $2.2 \times 10^{-11} \mathrm{~mol} /\left(\mathrm{cm}^{2} \mathrm{~s}\right)^{\mathrm{c}}$ & [159] \\
\hline & $\mathrm{Au}-\mathrm{PTFE} / \mathrm{Ti} / \mathrm{Si}$ & Xe lamp, $100 \mathrm{~mW} / \mathrm{cm}^{2}$ & $\mathrm{Na}_{2} \mathrm{SO}_{3}$ & $3.1 \times 10^{-10} \mathrm{~mol} /\left(\mathrm{cm}^{2} \mathrm{~s}\right)^{\mathrm{d}}$ & {$[162]$} \\
\hline
\end{tabular}

${ }^{a}$ Unless otherwise specified, the light intensities were not mentioned in the literature

${ }^{b}$ From given or calculated data based on reference data in the literature

${ }^{c}$ Operated without external applied potential

${ }^{\mathrm{d}}$ Operated under $-0.2 \mathrm{~V}_{\mathrm{RHE}}$

long-term reaction is also an issue for future applications [163]. More progress will be made with the development of characterization and calculation techniques.

\section{Plasma Catalysis for Ammonia Production}

Plasma catalysis has drawn attention in the past few decades as a possible alternative to the $\mathrm{H}-\mathrm{B}$ process for $\mathrm{NH}_{3}$ production $[14,34]$. By ionizing the source gases via an electric discharge, nonequilibrium plasma is generated; it contains highly excited atomic, molecular, ionic, and radical species. The energy transfer to form excited species is realized by collisions between reactant molecules and high-energy electrons, where the huge mass discrepancy results in the relatively low background temperature. For example, in nonthermal plasmas, the temperature of electrons reaches $10^{5} \mathrm{~K}$ because of their small mass, whereas large-mass ions/molecules and background gas are observed at RT. This finding is favorable for an exothermic process such as $\mathrm{NH}_{3}$ synthesis [164] and could also reduce sintering or coking of catalysts. The highly reactive electrons, ions, atoms, and radicals in the plasma also greatly boost the kinetics, enabling $\mathrm{NH}_{3}$ production at RT and atmospheric pressure [165].

On the other hand, the composition and properties of plasma are complicated, posing a challenge to the control and understanding of plasma-incorporated process, especially when catalysts are involved. For example, dielectric catalyst would change electric field distribution and affect the plasma characteristics [166]. In addition, the lifetime of short-lived active species can be extended on the catalyst surface, making the media more favorable for reaction [167].

As an external stimulus, plasma could also help heterogeneous catalysts to overcome scaling relations by converting $\mathrm{N}_{2}$ into vibrationally or electronically excited states, which decrease the activation energy for $\mathrm{N}_{2}$ dissociation without affecting subsequent reaction steps.

In a nonthermal plasma reactor induced by dielectric barrier discharge (DBD), the highest energy efficiency of $2.3 \mathrm{~g}$ $\mathrm{NH}_{3} / \mathrm{kWh}$ was achieved at a frequency of $10,000 \mathrm{~Hz}$, an applied voltage of $6000 \mathrm{~V}$, and a supplied $\mathrm{N}_{2} / \mathrm{H}_{2}$ ratio of 3:1. Ru catalyst with CNT support outperformed the others, where cesium acted as a promoter, and Molecular Sieve 13X and Amberlyst 15 served as microporous absorbents [168]. Iwamoto and colleagues [169] designed a wool-like copper electrode, which was found to be an effective catalyst for $\mathrm{NH}_{3}$ synthesis, using nonthermal atmospheric-pressure plasma by glow discharge. The energy efficiency of $\mathrm{NH}_{3}$ production reached $3.5 \%$ with an $\mathrm{NH}_{3}$ production rate of $3.3 \mathrm{~g}$ $\mathrm{NH}_{3} / \mathrm{kWh}$. The catalytic activity increased during reaction runs, and this phenomenon was also observed on a series of other wool-like metal electrodes. This finding might be due to the increased catalyst surface area [170]. Mehta et al. [38] demonstrated that DBD-induced nonthermal plasma could overcome the scaling relations through vibrational excitation of $\mathrm{N}_{2}$ in a plasma-enabled catalytic process. Based on a kinetic model that incorporates the effect of $\mathrm{N}_{2}$ vibrational excitation in a nonthermal plasma, they observed that $\mathrm{NH}_{3}$ production rates could be significantly improved over thermal catalytic rates at the same temperature and pressure. Additionally, the optimal catalyst shifted to sites that bind 
nitrogen weakly, such as $\mathrm{Co}$ and $\mathrm{Ni}$, instead of those for thermal catalysis, which were illustrated by both calculations and experiments (Fig. 14). This work represents the first demonstration of the computationally guided design of plasma-catalyst system for $\mathrm{NH}_{3}$ synthesis.

\section{Homogeneous Molecular Catalysis for Ammonia Production}

Another important artificial nitrogen fixation system focuses on stoichiometric transformation of coordinated dinitrogen or homogeneous catalytic reduction of $\mathrm{N}_{2}$ on transition metal-dinitrogen complexes [35]. As a synthetic functional analogue to nitrogenase, well-defined homogeneous catalysts allow researchers to gain more insights into the $\mathrm{N}_{2}$ reduction mechanism because these materials can be thoroughly investigated through various spectroscopic techniques, which aid in identifying molecular reactivity and elementary reactions that occur in nitrogenases. The first report of catalytic reduction of $\mathrm{N}_{2}$ by transition metal complexes came up in 2003, when Schrock and colleagues [171] synthesized a mononuclear molybdenum complex HIPTN $\mathrm{N}_{3} \mathrm{NMo}\left(\mathrm{N}_{2}\right)$ (HIPT refers to hexa-iso-propyl-terphenyl) to convert $\mathrm{N}_{2}$ into $\mathrm{NH}_{3}$, with 8 equivalents of ammonia per Mo atom. Nishibayashi and coworkers [172] observed that dimolybdenum-dinitrogen complex bearing 2,6-bis(di-tert-butylphosphinomethyl) pyridine pincer ligands acted as an effective catalyst for $\mathrm{N}_{2}$ reduction to $\mathrm{NH}_{3}$, with 23 equivalents of $\mathrm{NH}_{3}$ being generated (12 equivalents of $\mathrm{NH}_{3}$ produced per Mo atom). Early studies emphasized the effect of Mo as an essential element of nitrogenases. With the development of biochemical and spectroscopic studies on nitrogenase, $\mathrm{Fe}$ instead of Mo was determined as the site of $\mathrm{N}_{2}$ binding in the FeMo cofactor [8], and the central atom in FeMo cofactor was confirmed to be carbon [173, 174]. In 2011, Holland and coauthors [175] reported for the first time an example of complete stoichiometric $\mathrm{N}_{2}$ reduction by Fe complexes, although this reaction was not a catalytic process. A tris(phosphine)boranesupported iron complex was discovered in 2013; it catalyzes the reduction of $\mathrm{N}_{2}$ to $\mathrm{NH}_{3}$ under mild conditions, where a single iron site can stabilize various $\mathrm{N}_{x} \mathrm{H}_{y}$ intermediates generated during catalytic $\mathrm{N}_{2}$ reduction. A flexible iron-boron interaction possibly plays an important role in this catalytic process [176]. Holland further studied a synthetic complex with a sulfur-rich coordination sphere, which provides structural and spectroscopic implication for FeMoco- $\mathrm{N}_{2}$ binding and nitrogenase mechanism. The results illustrate that the sulfur-rich $\mathrm{Fe}$ site in the FeMoco causes $\mathrm{N}_{2}$ activation, and that $\mathrm{Fe}-\mathrm{S}$ bonds can be easily reduced and broken to allow $\mathrm{N}_{2}$ binding [177]. In addition to Mo- and Fe-based transition metal complexes, other molecular complexes incorporating metals, such as titanium and uranium, were also investigated to understand the mechanism behind enzymatic or thermal $\mathrm{NH}_{3}$ synthesis [178-180].

\section{Summary and Outlook}

Developing $\mathrm{NH}_{3}$ synthesis using sustainable or distributed approaches is becoming important to face the challenges of energy, environment, and transport issues. Homogeneous molecular catalysts are ideal for deep mechanism studies and show high activity due to their well-defined structures and facile mass transfer in the single liquid phase. Nonetheless, the difficulty in separating and recovering costly catalysts limits their practical applications. Heterogeneous catalysts normally possess complicated structures, where the exploration of the reaction mechanism is challenging. Still, these materials are the most widely studied catalysts for ENRR at present given their easy separation properties, relatively high activities, and great practical application potential.
Fig. 14 a Computed comparison of $\mathrm{N}_{2}$ vibrational-distribution-weighted (plasma-on) and thermal (plasma-off) $\mathrm{NH}_{3}$ synthesis rates on step sites. b Measured plasma-catalytic $\mathrm{NH}_{3}$ site-time yield on metal/ $\mathrm{Al}_{2} \mathrm{O}_{3}$ catalysts as a function of the DFT-calculated nitrogen adsorption energy. Reproduced with permission from Ref. [38]. Copyright 2018, Macmillan Publishers Limited
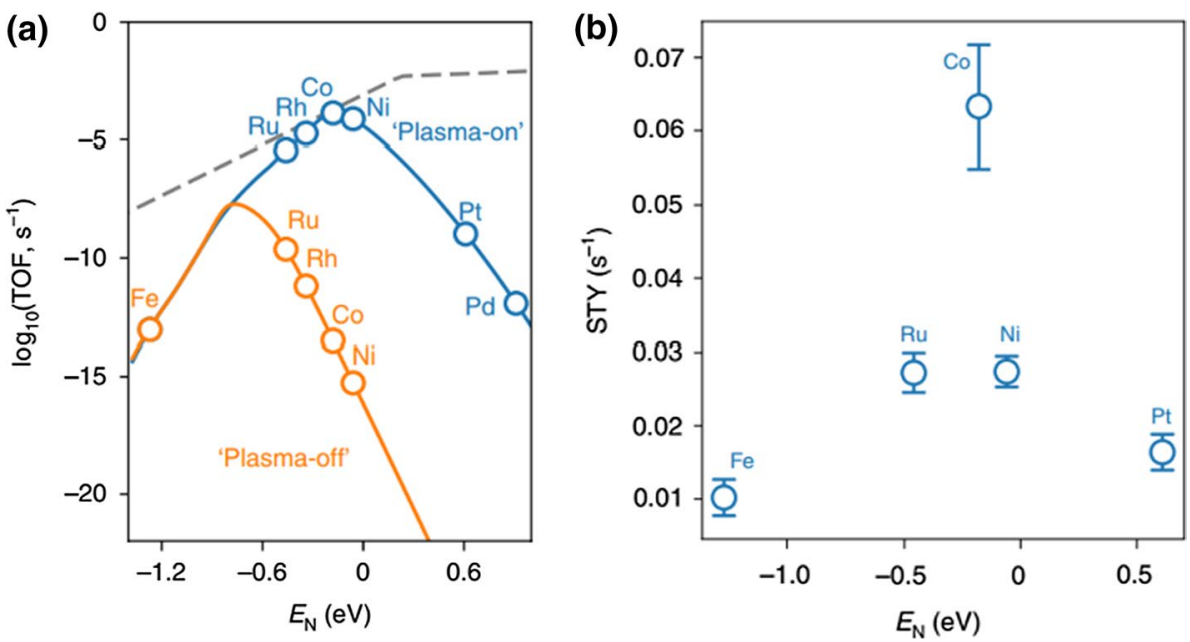
In an era when electricity is becoming more reliable for clean energy, electrochemical $\mathrm{NH}_{3}$ synthesis is highly expected. With a tremendous potential, this process will need considerable advancement toward practical applications and require a minimum production rate in the magnitude of $10^{-7} \mathrm{~mol} /\left(\mathrm{cm}^{2} \mathrm{~s}\right)$ [13]. In systems using aprotic electrolytes, the investigations should focus on enhancing current densities, improving catalyst/electrode lifetime, and reducing process temperatures. In systems using aqueous electrolytes, the utmost concern is how to prohibit HER as much as possible. Although limiting proton or electron availability at the electrode surface could improve the selectivity of $\mathrm{NH}_{3}$, it is not feasible for application under high current conditions.

Photocatalytic $\mathrm{NH}_{3}$ synthesis uses photo-responsive catalysts or photoelectrodes, and the yields demonstrated are still far from meeting the requirements for practical use. Standardization of the operation conditions is significant for future researchers for fair evaluation and comparison.

Electron transfer and reactions on the catalyst surface are critical steps in both electro- and photocatalytic $\mathrm{N}_{2}$ reduction. Therefore, surface reaction mechanism must be understood, and strategies that promote surface kinetics must be designed accordingly. Inspiration from enzymes and homogeneous systems demonstrate the potential to design complex active sites to improve catalyst performance at ambient conditions [181]. In situ characterization techniques, such as attenuated total reflectance-FTIR, SEIRAS, and in situ near ambient-pressure X-ray photo-electron spectroscopy, can detect reaction intermediates or active sites [81, 182]. Along with DFT simulations, the reaction mechanism and screen principles would be reasonably deduced [183]. Moreover, the structure of catalysts could be analyzed more precisely by X-ray absorption fine-structure and aberration-corrected TEM, which in turn contributes to the development of new catalytic materials such as single-atom catalysts [184-186]. In addition, designing new reaction configuration, such as semiconductor-biological systems [7], lithium cycling electrosynthesis [68], bio-electrochemical [187], or (solar thermal) chemical looping [188, 189], could decouple the linear scaling between nitrogen-binding energy and activation barrier for $\mathrm{N}_{2}$ dissociation [190].

Considering the small $\mathrm{NH}_{3}$ yield at present, a significant issue in (photo)electrocatalytic $\mathrm{NH}_{3}$ synthesis is the rigorous protocol to prove that $\mathrm{NH}_{3}$ truly comes from $\mathrm{N}_{2}$ reduction. Ammonia contamination is caused by various potential sources during an experiment cycle, which would lead to a fake positive result. Special attention must be paid to catalysts that are either nitrogen-containing or prepared from nitrogen-containing precursors. In the premise of eliminating every possible exogenous contamination, a proper ${ }^{15} \mathrm{~N}_{2}$ control experiment is essential before drawing a convincing conclusion. In addition, utilizing various $\mathrm{NH}_{3}$ detection methods simultaneously could make the results more accurate (for instance, NMR/indophenol method).

In plasma-enabled catalytic $\mathrm{NH}_{3}$ synthesis, limited knowledge is available about the fundamental reaction mechanisms of the activated species. Further development in this direction could draw inspiration from traditional heterogeneous catalysis and focus on building kinetic models, which are based on in situ characterization and computational simulations.

Although molecular catalysis for $\mathrm{N}_{2}$ reduction still requires development toward practical use, catalytic systems for $\mathrm{N}_{2}$ fixation have been successfully developed, and molecular structures that reveal essential components for the $\mathrm{N}_{2}$ reduction mechanism have been offered. More insightful molecule design and experimental/theoretical investigations could broaden the understanding behind reactions, providing insights into the design of heterogeneous catalysts.

Overall, flourishing alternative catalytic systems have been making great contributions to $\mathrm{N}_{2}$ reduction reaction. With the intensive and collaborative research worldwide, sustainable $\mathrm{NH}_{3}$ synthesis will eventually arrive and create renewable wealth for human society.

Open Access This article is licensed under a Creative Commons Attribution 4.0 International License, which permits use, sharing, adaptation, distribution and reproduction in any medium or format, as long as you give appropriate credit to the original author(s) and the source, provide a link to the Creative Commons licence, and indicate if changes were made. The images or other third party material in this article are included in the article's Creative Commons licence, unless indicated otherwise in a credit line to the material. If material is not included in the article's Creative Commons licence and your intended use is not permitted by statutory regulation or exceeds the permitted use, you will need to obtain permission directly from the copyright holder. To view a copy of this licence, visit http://creativecommons.org/licenses/by/4.0/.

\section{References}

1. Rosca V, Duca M, de Groot MT et al (2009) Nitrogen cycle electrocatalysis. Chem Rev 109(6):2209-2244

2. Jia HP, Quadrelli EA (2014) Mechanistic aspects of dinitrogen cleavage and hydrogenation to produce ammonia in catalysis and organometallic chemistry: relevance of metal hydride bonds and dihydrogen. Chem Soc Rev 43(2):547-564

3. Allen MB, Arnon DI (1955) Studies on nitrogen-fixing bluegreen algae. I. Growth and nitrogen fixation by Anabaena cylindrica lemm. Plant Physiol 30(4):366-372

4. Houlton BZ, Wang YP, Vitousek PM et al (2008) A unifying framework for dinitrogen fixation in the terrestrial biosphere. Nature 454(7202):327-330

5. Salvagiotti F, Cassman KG, Specht JE et al (2008) Nitrogen uptake, fixation and response to fertilizer $\mathrm{N}$ in soybeans: a review. Field Crop Res 108(1):1-13

6. Hoffman BM, Lukoyanov D, Yang ZY et al (2014) Mechanism of nitrogen fixation by nitrogenase: the next stage. Chem Rev 114(8):4041-4062 
7. Brown KA, Harris DF, Wilker MB et al (2016) Light-driven dinitrogen reduction catalyzed by a CdS: nitrogenase MoFe protein biohybrid. Science 352(6284):448-450

8. Hoffman BM, Dean DR, Seefeldt LC (2009) Climbing nitrogenase: toward a mechanism of enzymatic nitrogen fixation. Acc Chem Res 42(5):609-619

9. Raugei S, Seefeldt LC, Hoffman BM (2018) Critical computational analysis illuminates the reductive-elimination mechanism that activates nitrogenase for $\mathrm{N}_{2}$ reduction. Proc Natl Acad Sci 115(45):E10521-E10530

10. Čorić I, Holland PL (2016) Insight into the iron-molybdenum cofactor of nitrogenase from synthetic iron complexes with sulfur, carbon, and hydride ligands. J Am Chem Soc 138(23):7200-7211

11. Smil V (1999) Detonator of the population explosion. Nature 400(6743):415

12. Fowler D, Coyle M, Skiba U et al (2013) The global nitrogen cycle in the twenty-first century. Philos Trans R Soc B 368(1621):20130164

13. Giddey S, Badwal SPS, Kulkarni A (2013) Review of electrochemical ammonia production technologies and materials. Int J Hydrog Energy 38(34):14576-14594

14. Patil BS, Wang Q, Hessel V et al (2015) Plasma $\mathrm{N}_{2}$-fixation: 1900-2014. Catal Today 256:49-66

15. Christensen CH, Johannessen T, Sørensen RZ et al (2006) Towards an ammonia-mediated hydrogen economy? Catal Today 111(1-2):140-144

16. Klerke A, Christensen CH, Nørskov JK et al (2008) Ammonia for hydrogen storage: challenges and opportunities. J Mater Chem 18(20):2304-2310

17. Erisman JW, Sutton MA, Galloway J et al (2008) How a century of ammonia synthesis changed the world. Nat Geosci 1(10):636-639

18. Howarth RW (2008) Coastal nitrogen pollution: a review of sources and trends globally and regionally. Harmful Algae $8(1): 14-20$

19. Wang L, Xia MK, Wang $\mathrm{H}$ et al (2018) Greening ammonia toward the solar ammonia refinery. Joule 2(6):1055-1074

20. Jackson RB, Canadell JG, Le Quéré C et al (2016) Reaching peak emissions. Nat Clim Change 6(1):7-10

21. Brethomé FM, Williams NJ, Seipp CA et al (2018) Direct air capture of $\mathrm{CO}_{2}$ via aqueous-phase absorption and crystallinephase release using concentrated solar power. Nat Energy 3(7):553-559

22. Chen JG, Crooks RM, Seefeldt LC et al (2018) Beyond fossil fuel-driven nitrogen transformations. Science 360(6391):eaar6611

23. Medford AJ, Hatzell MC (2017) Photon-driven nitrogen fixation: current progress, thermodynamic considerations, and future outlook. ACS Catal 7(4):2624-2643

24. Cui XY, Tang C, Zhang Q (2018) A review of electrocatalytic reduction of dinitrogen to ammonia under ambient conditions. Adv Energy Mater 8(22): 1800369

25. Wang K, Smith D, Zheng Y (2018) Electron-driven heterogeneous catalytic synthesis of ammonia: current states and perspective. Carbon Resour Convers 1(1):2-31

26. Kyriakou V, Garagounis I, Vasileiou E et al (2017) Progress in the electrochemical synthesis of ammonia. Catal Today 286:2-13

27. Shipman MA, Symes MD (2017) Recent progress towards the electrosynthesis of ammonia from sustainable resources. Catal Today 286:57-68

28. Renner JN, Greenlee LF, Ayres KE et al (2015) Electrochemical synthesis of ammonia: a low pressure, low temperature approach. Electrochem Soc Interface 24(2):51-57

29. Guo CX, Ran JR, Vasileff A et al (2018) Rational design of electrocatalysts and photo(electro)catalysts for nitrogen reduction to ammonia $\left(\mathrm{NH}_{3}\right)$ under ambient conditions. Energy Environ Sci 11(1):45-56

30. Amar IA, Lan R, Petit CTG et al (2011) Solid-state electrochemical synthesis of ammonia: a review. J Solid State Electrochem 15(9): 1845-1860

31. Li J, Li H, Zhan GM et al (2017) Solar water splitting and nitrogen fixation with layered bismuth oxyhalides. Acc Chem Res 50(1):112-121

32. Yang JH, Guo YZ, Lu WZ et al (2018) Emerging applications of plasmons in driving $\mathrm{CO}_{2}$ reduction and $\mathrm{N}_{2}$ fixation. Adv Mater 30(48):1802227

33. Chen XZ, Li N, Kong ZZ et al (2018) Photocatalytic fixation of nitrogen to ammonia: state-of-the-art advancements and future prospects. Mater Horiz 5(1):9-27

34. Hong J, Prawer S, Murphy AB (2018) Plasma catalysis as an alternative route for ammonia production: status, mechanisms, and prospects for progress. ACS Sustain Chem Eng 6(1):15-31

35. MacLeod KC, Holland PL (2013) Recent developments in the homogeneous reduction of dinitrogen by molybdenum and iron. Nat Chem 5(7):559-565

36. Licht S, Cui B, Wang B et al (2014) Ammonia synthesis by $\mathrm{N}_{2}$ and steam electrolysis in molten hydroxide suspensions of nanoscale $\mathrm{Fe}_{2} \mathrm{O}_{3}$. Science 345(6197):637-640

37. Marnellos G, Stoukides M (1998) Ammonia synthesis at atmospheric pressure. Science 282(5386):98-100

38. Mehta P, Barboun P, Herrera FA et al (2018) Overcoming ammonia synthesis scaling relations with plasma-enabled catalysis. Nat Catal 1(4):269-275

39. Li CC, Wang T, Zhao ZJ et al (2018) Promoted fixation of molecular nitrogen with surface oxygen vacancies on plasmon-enhanced $\mathrm{TiO}_{2}$ photoelectrodes. Angew Chem Int Ed 57(19):5278-5282

40. Greenlee LF, Renner JN, Foster SL (2018) The use of controls for consistent and accurate measurements of electrocatalytic ammonia synthesis from dinitrogen. ACS Catal 8(9):7820-7827

41. Iwahara H, Esaka T, Uchida $H$ et al (1981) Proton conduction in sintered oxides and its application to steam electrolysis for hydrogen production. Solid State Ionics 3-4:359-363

42. Garagounis I, Kyriakou V, Skodra A et al (2014) Electrochemical synthesis of ammonia in solid electrolyte cells. Front Energy Res 2(1): $1-10$

43. Marnellos G, Zisekas S, Stoukides M (2000) Synthesis of ammonia at atmospheric pressure with the use of solid state proton conductors. J Catal 193(1):80-87

44. Li Z, Liu R, Wang J et al (2007) Preparation of double-doped $\mathrm{BaCeO}_{3}$ and its application in the synthesis of ammonia at atmospheric pressure. Sci Technol Adv Mater 8(7-8):566-570

45. Xie YH, Wang JD, Liu RQ et al (2004) Preparation of $\mathrm{La}_{1.9} \mathrm{Ca}_{0.1} \mathrm{Zr}_{2} \mathrm{O}_{6.95}$ with pyrochlore structure and its application in synthesis of ammonia at atmospheric pressure. Solid State Ionics 168(1): 117-121

46. Wang JD, Xie YH, Zhang ZF et al (2005) Protonic conduction in $\mathrm{Ca}^{2+}$-doped $\mathrm{La}_{2} \mathrm{M}_{2} \mathrm{O}_{7}(\mathrm{M}=\mathrm{Ce}, \mathrm{Zr})$ with its application to ammonia synthesis electrochemically. Mater Res Bull 40(8):1294-1302

47. Liu RQ, Xie YH, Wang JD et al (2006) Synthesis of ammonia at atmospheric pressure with $\mathrm{Ce}_{0.8} \mathrm{M}_{0.2} \mathrm{O}_{2-\delta}(\mathrm{M}=\mathrm{La}, \mathrm{Y}, \mathrm{Gd}, \mathrm{Sm})$ and their proton conduction at intermediate temperature. Solid State Ionics 177(1-2):73-76

48. Xu G, Liu R, Wang J (2009) Electrochemical synthesis of ammonia using a cell with a Nafion membrane and $\mathrm{SmFe}_{0.7} \mathrm{Cu}_{0.3-x}$ $\mathrm{Ni}_{x} \mathrm{O}_{3}(x=0-0.3)$ cathode at atmospheric pressure and lower temperature. Sci China Ser B 52(8):1171-1175

49. Liu R, Xu G (2010) Comparison of electrochemical synthesis of ammonia by using sulfonated polysulfone and Nafion membrane with $\mathrm{Sm}_{1.5} \mathrm{Sr}_{0.5} \mathrm{NiO}_{4}$. Chin J Chem 28(2):139-142 
50. Zhang ZF, Zhong ZP, Liu RQ (2010) Cathode catalysis performance of $\mathrm{SmBaCuMO} 5+\delta(\mathrm{M}=\mathrm{Fe} \mathrm{Co}, \mathrm{Ni})$ in ammonia synthesis. J Rare Earths 28(4):556-559

51. Amar IA, Lan R, Petit CTG et al (2011) Electrochemical synthesis of ammonia based on a carbonate-oxide composite electrolyte. Solid State Ionics 182(1):133-138

52. Wang BH, Wang JD, Liu RQ et al (2006) Synthesis of ammonia from natural gas at atmospheric pressure with doped ceria$\mathrm{Ca} 3(\mathrm{PO} 4), 2-\mathrm{K} 3 \mathrm{PO} 4$ composite electrolyte and its proton conductivity at intermediate temperature. J Solid State Electrochem 11(1):27-31

53. Chen C, Ma GL (2009) Proton conduction in $\mathrm{BaCe}_{1-x} \mathrm{Gd}_{x} \mathrm{O}_{3-\alpha}$ at intermediate temperature and its application to synthesis of ammonia at atmospheric pressure. J Alloy Compd 485(1-2):69-72

54. Kordali V, Kyriacou G, Lambrou C (2000) Electrochemical synthesis of ammonia at atmospheric pressure and low temperature in a solid polymer electrolyte cell. Chem Commun 17:1673-1674

55. Skodra A, Stoukides M (2009) Electrocatalytic synthesis of ammonia from steam and nitrogen at atmospheric pressure. Solid State Ionics 180(23-25):1332-1336

56. Amar IA, Lan R, Tao SW (2015) Synthesis of ammonia directly from wet nitrogen using a redox stable $\mathrm{La}_{0.75} \mathrm{Sr}_{0.25} \mathrm{Cr}_{0.5} \mathrm{Fe}_{0.5} \mathrm{O}_{3-\delta}$ $\mathrm{Ce}_{0.8} \mathrm{Gd}_{0.18} \mathrm{Ca}_{0.02} \mathrm{O}_{2-\delta}$ composite cathode. RSC $\mathrm{Adv}$ 5(49):38977-38983

57. Goto T, Tada M, Ito Y (1997) Electrochemical behavior of nitride ions in a molten chloride system. J Electrochem Soc 144(7):2271-2276

58. Goto T, Ito Y (1998) Electrochemical reduction of nitrogen gas in a molten chloride system. Electrochim Acta 43(21-22):3379-3384

59. Murakami T, Nishikiori T, Nohira T et al (2003) Electrolytic synthesis of ammonia in molten salts under atmospheric pressure. J Am Chem Soc 125(2):334-335

60. Murakami T, Nishikiori T, Nohira T et al (2005) Investigation of anodic reaction of electrolytic ammonia synthesis in molten salts under atmospheric pressure. J Electrochem Soc 152(5):D75-D78

61. Serizawa N, Miyashiro H, Takei K et al (2012) Dissolution behavior of ammonia electrosynthesized in molten $\mathrm{LiCl}-\mathrm{KCl}-$ CsCl system. J Electrochem Soc 159(4):E87-E91

62. Murakami T, Nohira T, Goto T et al (2005) Electrolytic ammonia synthesis from water and nitrogen gas in molten salt under atmospheric pressure. Electrochim Acta 50(27):5423-5426

63. Murakami T, Nohira T, Araki Y et al (2007) Electrolytic synthesis of ammonia from water and nitrogen under atmospheric pressure using a boron-doped diamond electrode as a nonconsumable anode. Electrochem Solid State Lett 10(4):E4-E6

64. Murakami T, Nishikiori T, Nohira T et al (2005) Electrolytic ammonia synthesis from hydrogen chloride and nitrogen gases with simultaneous recovery of chlorine under atmospheric pressure. Electrochem Solid State Lett 8(8):D19-D21

65. Murakami T, Nohira T, Ogata YH et al (2005) Electrochemical synthesis of ammonia and coproduction of metal sulfides from hydrogen sulfide and nitrogen under atmospheric pressure. J Electrochem Soc 152(6):D109-D112

66. Murakami T, Nohira T, Ogata YH et al (2005) Electrolytic ammonia synthesis in molten salts under atmospheric pressure using methane as a hydrogen source. Electrochem Solid State Lett 8(4):D12-D14

67. Li FF, Licht S (2014) Advances in understanding the mechanism and improved stability of the synthesis of ammonia from air and water in hydroxide suspensions of nanoscale $\mathrm{Fe}_{2} \mathrm{O}_{3}$. Inorg Chem 53(19):10042-10044

68. McEnaney JM, Singh AR, Schwalbe JA et al (2017) Ammonia synthesis from $\mathrm{N}_{2}$ and $\mathrm{H}_{2} \mathrm{O}$ using a lithium cycling electrification strategy at atmospheric pressure. Energy Environ Sci 10(7):1621-1630

69. Montoya JH, Tsai C, Vojvodic A et al (2015) The challenge of electrochemical ammonia synthesis: a new perspective on the role of nitrogen scaling relations. Chemsuschem 8(13):2180-2186

70. van der Ham CJM, Koper MTM, Hetterscheid DGH (2014) Challenges in reduction of dinitrogen by proton and electron transfer. Chem Soc Rev 43(15):5183-5191

71. Ertl G (2008) Reactions at surfaces: from atoms to complexity (nobel lecture). Angew Chem Int Ed 47(19):3524-3535

72. Skúlason E, Bligaard T, Gudmundsdóttir S et al (2012) A theoretical evaluation of possible transition metal electro-catalysts for $\mathrm{N}_{2}$ reduction. Phys Chem Chem Phys 14(3):1235-1245

73. Suryanto BHR, Du HL, Wang DB et al (2019) Challenges and prospects in the catalysis of electroreduction of nitrogen to ammonia. Nat Catal 2(4):290-296

74. Deng GR, Wang T, Alshehri AA et al (2019) Improving the electrocatalytic $\mathrm{N}_{2}$ reduction activity of Pd nanoparticles through surface modification. J Mater Chem A 7(38):21674-21677

75. Wu TW, Zhu XJ, Xing Z et al (2019) Greatly improving electrochemical $\mathrm{N}_{2}$ reduction over $\mathrm{TiO}_{2}$ nanoparticles by iron doping. Angew Chem Int Ed 58(51):18449-18453

76. Xie HT, Geng Q, Zhu XJ et al (2019) $\mathrm{PdP}_{2}$ nanoparticles-reduced graphene oxide for electrocatalytic $\mathrm{N}_{2}$ conversion to $\mathrm{NH}_{3}$ under ambient conditions. J Mater Chem A 7(43):24760-24764

77. Zhang R, Ji L, Kong WH et al (2019) Electrocatalytic $\mathrm{N}_{2}$-to- $\mathrm{NH}_{3}$ conversion with high faradaic efficiency enabled using a $\mathrm{Bi}$ nanosheet array. Chem Commun 55(36):5263-5266

78. Li Y, Li T, Zhu X et al (2020) $\mathrm{DyF}_{3}$ : an efficient electrocatalyst for $\mathrm{N}_{2}$ fixation to $\mathrm{NH}_{3}$ under ambient conditions. Chem Asian $\mathrm{J}$ 15(4):487-489

79. Zhao RB, Liu CW, Zhang $X X$ et al (2020) An ultrasmall $\mathrm{Ru}_{2} \mathrm{P}$ nanoparticles-reduced graphene oxide hybrid: an efficient electrocatalyst for $\mathrm{NH}_{3}$ synthesis under ambient conditions. J Mater Chem A 8(1):77-81

80. Zhu XJ, Mou SY, Peng QL et al (2020) Aqueous electrocatalytic $\mathrm{N}_{2}$ reduction for ambient $\mathrm{NH}_{3}$ synthesis: recent advances in catalyst development and performance improvement. J Mater Chem A 8(4):1545-1556

81. Yao ZhuSQ, Wang HJ et al (2018) A spectroscopic study on the nitrogen electrochemical reduction reaction on gold and platinum surfaces. J Am Chem Soc 140(4):1496-1501

82. Yang DS, Chen T, Wang ZJ (2017) Electrochemical reduction of aqueous nitrogen $\left(\mathrm{N}_{2}\right)$ at a low overpotential on (110)-oriented Mo nanofilm. J Mater Chem A 5(36):18967-18971

83. Bao D, Zhang Q, Meng FL et al (2017) Electrochemical reduction of $\mathrm{N}_{2}$ under ambient conditions for artificial $\mathrm{N}_{2}$ fixation and renewable energy storage using $\mathrm{N}_{2} / \mathrm{NH}_{3}$ cycle. Adv Mater 29(3): 1604799

84. Shi MM, Bao D, Wulan BR et al (2017) Au sub-nanoclusters on $\mathrm{TiO}_{2}$ toward highly efficient and selective electrocatalyst for $\mathrm{N}_{2}$ conversion to $\mathrm{NH}_{3}$ at ambient conditions. Adv Mater 29(17): 1606550

85. Li SJ, Bao D, Shi MM et al (2017) Amorphizing of Au nanoparticles by $\mathrm{CeO}_{x}-\mathrm{RGO}$ hybrid support towards highly efficient electrocatalyst for $\mathrm{N}_{2}$ reduction under ambient conditions. Adv Mater 29(33):1700001

86. Wang J, Yu L, Hu L et al (2018) Ambient ammonia synthesis via palladium-catalyzed electrohydrogenation of dinitrogen at low overpotential. Nat Commun 9(1):1795

87. Hao YC, Guo Y, Chen LW et al (2019) Promoting nitrogen electroreduction to ammonia with bismuth nanocrystals and potassium cations in water. Nat Catal 2(5):448-456 
88. Nguyen M-T, Seriani N, Gebauer R (2015) Nitrogen electrochemically reduced to ammonia with hematite: density-functional insights. Phys Chem Chem Phys 17(22):14317-14322

89. Chen SM, Perathoner S, Ampelli C et al (2017) Room-temperature electrocatalytic synthesis of $\mathrm{NH}_{3}$ from $\mathrm{H}_{2} \mathrm{O}$ and $\mathrm{N}_{2}$ in a gas-liquid-solid three-phase reactor. ACS Sustain Chem Eng 5(8):7393-7400

90. Kong JM, Lim A, Yoon C et al (2017) Electrochemical synthesis of $\mathrm{NH}_{3}$ at low temperature and atmospheric pressure using a $\gamma$ - $\mathrm{Fe}_{2} \mathrm{O}_{3}$ catalyst. ACS Sustain Chem Eng 5(11):10986-10995

91. Chen SM, Perathoner S, Ampelli C et al (2017) Electrocatalytic synthesis of ammonia at room temperature and atmospheric pressure from water and nitrogen on a carbon-nanotube-based electrocatalyst. Angew Chem Int Ed 56(10):2699-2703

92. Xiang XJ, Wang Z, Shi XF et al (2018) Ammonia synthesis from electrocatalytic $\mathrm{N}_{2}$ reduction under ambient conditions by $\mathrm{Fe}_{2} \mathrm{O}_{3}$ nanorods. ChemCatChem 10(20):4530-4535

93. Lv C, Yan CS, Chen G et al (2018) An amorphous noblemetal-free electrocatalyst that enables nitrogen fixation under ambient conditions. Angew Chem Int Ed 130(21):6181-6184

94. Zhang L, Ji XQ, Ren X et al (2018) Electrochemical ammonia synthesis via nitrogen reduction reaction on a $\mathrm{MoS}_{2}$ catalyst: theoretical and experimental studies. Adv Mater 30(28): 1800191

95. Li XH, Li TS, Ma YJ et al (2018) Boosted electrocatalytic $\mathrm{N}_{2}$ reduction to $\mathrm{NH}_{3}$ by defect-rich $\mathrm{MoS}_{2}$ nanoflower. Adv Energy Mater 8(30):1801357

96. Azofra LM, Sun CH, Cavallo L et al (2017) Feasibility of $\mathrm{N}_{2}$ binding and reduction to ammonia on Fe-deposited $\mathrm{MoS}_{2} 2 \mathrm{D}$ sheets: a DFT study. Chem Eur J 23(34):8275-8279

97. Suryanto BHR, Wang DB, Azofra LM et al (2019) $\mathrm{MoS}_{2}$ polymorphic engineering enhances selectivity in the electrochemical reduction of nitrogen to ammonia. ACS Energy Lett 4(2):430-435

98. Azofra LM, Li N, MacFarlane DR et al (2016) Promising prospects for $2 \mathrm{D} \mathrm{d}^{2}-\mathrm{d}^{4} \mathrm{M}_{3} \mathrm{C}_{2}$ transition metal carbides (MXenes) in $\mathrm{N}_{2}$ capture and conversion into ammonia. Energy Environ Sci 9(8):2545-2549

99. Cheng H, Ding LX, Chen GF et al (2018) Molybdenum carbide nanodots enable efficient electrocatalytic nitrogen fixation under ambient conditions. Adv Mater 30(46):1803694

100. Abghoui Y, Garden AL, Hlynsson VF et al (2015) Enabling electrochemical reduction of nitrogen to ammonia at ambient conditions through rational catalyst design. Phys Chem Chem Phys 17(7):4909-4918

101. Abghoui Y, Skúlason E (2017) Electrochemical synthesis of ammonia via Mars-van Krevelen mechanism on the (111) facets of group III-VII transition metal mononitrides. Catal Today 286:78-84

102. Abghoui Y, Garden AL, Howalt JG et al (2016) Electroreduction of $\mathrm{N}_{2}$ to ammonia at ambient conditions on mononitrides of $\mathrm{Zr}, \mathrm{Nb}, \mathrm{Cr}$, and $\mathrm{V}$ : a DFT guide for experiments. ACS Catal 6(2):635-646

103. Abghoui Y, Skúlason E (2017) Onset potentials for different reaction mechanisms of nitrogen activation to ammonia on transition metal nitride electro-catalysts. Catal Today 286:69-77

104. Yang X, Nash J, Anibal J et al (2018) Mechanistic insights into electrochemical nitrogen reduction reaction on vanadium nitride nanoparticles. J Am Chem Soc 140(41):13387-13391

105. Li QY, He LZ, Sun CH et al (2017) Computational study of $\mathrm{MoN}_{2}$ monolayer as electrochemical catalysts for nitrogen reduction. J Phys Chem C 121(49):27563-27568

106. Zhang L, Ji XQ, Ren X et al (2018) Efficient electrochemical $\mathrm{N}_{2}$ reduction to $\mathrm{NH}_{3}$ on MoN nanosheets array under ambient conditions. ACS Sustain Chem Eng 6(8):9550-9554
107. Wang H, Wang L, Wang Q et al (2018) Ambient electrosynthesis of ammonia: electrode porosity and composition engineering. Angew Chem Int Ed 57(38):12360-12364

108. Liu YM, Su Y, Quan X et al (2018) Facile ammonia synthesis from electrocatalytic $\mathrm{N}_{2}$ reduction under ambient conditions on $\mathrm{N}$-doped porous carbon. ACS Catal 8(2):1186-1191

109. Lv C, Qian YM, Yan CS et al (2018) Defect engineering metalfree polymeric carbon nitride electrocatalyst for effective nitrogen fixation under ambient conditions. Angew Chem Int Ed 57(32):10246-10250

110. Zhang LL, Ding LX, Chen GF et al (2019) Ammonia synthesis under ambient conditions: selective electroreduction of dinitrogen to ammonia on black phosphorus nanosheets. Angew Chem Int Ed 131(9):2638-2642

111. Milton RD, Cai R, Abdellaoui S et al (2017) Bioelectrochemical Haber-Bosch process: an ammonia-producing $\mathrm{H}_{2} / \mathrm{N}_{2}$ fuel cell. Angew Chem Int Ed 56(10):2680-2683

112. Ma JL, Bao D, Shi MM et al (2017) Reversible nitrogen fixation based on a rechargeable lithium-nitrogen battery for energy storage. Chemistry 2(4):525-532

113. Shi MM, Bao D, Li SJ et al (2018) Anchoring PdCu amorphous nanocluster on graphene for electrochemical reduction of $\mathrm{N}_{2}$ to $\mathrm{NH}_{3}$ under ambient conditions in aqueous solution. Adv Energy Mater 8(21): 1800124

114. Liu HM, Han SH, Zhao Y et al (2018) Surfactant-free atomically ultrathin rhodium nanosheet nanoassemblies for efficient nitrogen electroreduction. J Mater Chem A 6(7):3211-3217

115. Han JR, Liu ZC, Ma YJ et al (2018) Ambient $\mathrm{N}_{2}$ fixation to $\mathrm{NH}_{3}$ at ambient conditions: using $\mathrm{Nb}_{2} \mathrm{O}_{5}$ nanofiber as a highperformance electrocatalyst. Nano Energy 52:264-270

116. Singh AR, Rohr BA, Schwalbe JA et al (2017) Electrochemical ammonia synthesis-The selectivity challenge. ACS Catal 7(1):706-709

117. Zhou FL, Azofra LM, Ali M et al (2017) Electro-synthesis of ammonia from nitrogen at ambient temperature and pressure in ionic liquids. Energy Environ Sci 10(12):2516-2520

118. Tsuneto A, Kudo A, Sakata T (1993) Efficient electrochemical reduction of $\mathrm{N}_{2}$ to $\mathrm{NH}_{3}$ catalyzed by lithium. Chem Lett 22(5):851-854

119. Lee HK, Koh CSL, Lee YH et al (2018) Favoring the unfavored: selective electrochemical nitrogen fixation using a reticular chemistry approach. Sci Adv 4(3):eaar3208

120. Andersen SZ, Čolić V, Yang S et al (2019) A rigorous electrochemical ammonia synthesis protocol with quantitative isotope measurements. Nature 570(7762):504-508

121. Dabundo R, Lehmann MF, Treibergs L et al (2014) The contamination of commercial $15 \mathrm{~N}_{2}$ gas stocks with $15 \mathrm{~N}$-labeled nitrate and ammonium and consequences for nitrogen fixation measurements. PLoS One 9(10):e110335

122. Han C, Qi MY, Tang ZR et al (2019) Gold nanorods-based hybrids with tailored structures for photoredox catalysis: fundamental science, materials design and applications. Nano Today 27:48-72

123. Tang ZR, Han B, Han C et al (2017) One dimensional CdS based materials for artificial photoredox reactions. J Mater Chem A 5(6):2387-2410

124. Schrauzer GN, Strampach N, Hui LN et al (1983) Nitrogen photoreduction on desert sands under sterile conditions. Proc Natl Acad Sci 80(12):3873-3876

125. Schrauzer GN, Guth TD (1977) Photolysis of water and photoreduction of nitrogen on titanium dioxide. J Am Chem Soc 99(22):7189-7193

126. Endoh E, Leland JK, Bard AJ (1986) Heterogeneous photoreduction of nitrogen to ammonia on tungsten oxide. J Phys Chem 90(23):6223-6226 
127. Khader MM, Lichtin NN, Vurens GH et al (1987) Photoassisted catalytic dissociation of water and reduction of nitrogen to ammonia on partially reduced ferric oxide. Langmuir 3(2):303-304

128. Ranjit KT, Varadarajan TK, Viswanathan B (1996) Photocatalytic reduction of dinitrogen to ammonia over noble-metal-loaded $\mathrm{TiO}_{2}$. J Photochem Photobiol A Chem 96(1-3):181-185

129. Hoshino K, Inui M, Kitamura T et al (2000) Fixation of dinitrogen to a mesoscale solid salt using a titanium oxide/conducting polymer system. Angew Chem Int Ed 39(14):2509-2512

130. Rusina O, Eremenko A, Frank G et al (2001) Nitrogen photofixation at nanostructured iron titanate films. Angew Chem Int Ed 40(21):3993-3995

131. Zhao WR, Zhang J, Zhu X et al (2014) Enhanced nitrogen photofixation on Fe-doped $\mathrm{TiO}_{2}$ with highly exposed (101) facets in the presence of ethanol as scavenger. Appl Catal B Environ 144:468-477

132. Hirakawa H, Hashimoto M, Shiraishi Y et al (2017) Photocatalytic conversion of nitrogen to ammonia with water on surface oxygen vacancies of titanium dioxide. J Am Chem Soc 139(31):10929-10936

133. Kong M, Li YZ, Chen X et al (2011) Tuning the relative concentration ratio of bulk defects to surface defects in $\mathrm{TiO}_{2}$ nanocrystals leads to high photocatalytic efficiency. J Am Chem Soc 133(41):16414-16417

134. Yang JH, Guo YZ, Jiang RB et al (2018) High-efficiency "working-in-tandem" nitrogen photofixation achieved by assembling plasmonic gold nanocrystals on ultrathin titania nanosheets. J Am Chem Soc 140(27):8497-8508

135. Li H, Shang J, Ai ZH et al (2015) Efficient visible light nitrogen fixation with $\mathrm{BiOBr}$ nanosheets of oxygen vacancies on the exposed 001 facets. J Am Chem Soc 137(19):6393-6399

136. Li H, Shang J, Shi JG et al (2016) Facet-dependent solar ammonia synthesis of $\mathrm{BiOCl}$ nanosheets via a proton-assisted electron transfer pathway. Nanoscale 8(4):1986-1993

137. Dong GH, Ho W, Wang CY (2015) Selective photocatalytic $\mathrm{N}_{2}$ fixation dependent on $\mathrm{g}-\mathrm{C}_{3} \mathrm{~N}_{4}$ induced by nitrogen vacancies. $\mathrm{J}$ Mater Chem A 3(46):23435-23441

138. Cao SH, Zhou N, Gao FH et al (2017) All-solid-state $\mathrm{Z}$-scheme 3,4-dihydroxybenzaldehyde-functionalized $\mathrm{Ga}_{2} \mathrm{O}_{3} /$ graphitic carbon nitride photocatalyst with aromatic rings as electron mediators for visible-light photocatalytic nitrogen fixation. Appl Catal B Environ 218:600-610

139. Hu SZ, Chen $\mathrm{X}$, Li Q et al (2017) $\mathrm{Fe}^{3+}$ doping promoted $\mathrm{N}_{2}$ photofixation ability of honeycombed graphitic carbon nitride: the experimental and density functional theory simulation analysis. Appl Catal B Environ 201:58-69

140. Hu SZ, Qu XY, Bai J et al (2017) Effect of Cu(I)-N active sites on the $\mathrm{N}_{2}$ photofixation ability over flowerlike copper-doped g- $\mathrm{C}_{3} \mathrm{~N}_{4}$ prepared via a novel molten salt-assisted microwave process: the experimental and density functional theory simulation analysis. ACS Sustain Chem Eng 5(8):6863-6872

141. Cao SH, Chen H, Jiang F et al (2018) Nitrogen photofixation by ultrathin amine-functionalized graphitic carbon nitride nanosheets as a gaseous product from thermal polymerization of urea. Appl Catal B Environ 224:222-229

142. Liu QX, Ai LH, Jiang J (2018) MXene-derived $\mathrm{TiO}_{2} @ \mathrm{C} / \mathrm{g}-\mathrm{C}_{3} \mathrm{~N}_{4}$ heterojunctions for highly efficient nitrogen photofixation. J Mater Chem A 6(9):4102-4110

143. Qiu PX, Xu CM, Zhou N et al (2018) Metal-free black phosphorus nanosheets-decorated graphitic carbon nitride nanosheets with $\mathrm{CP}$ bonds for excellent photocatalytic nitrogen fixation. Appl Catal B Environ 221:27-35

144. Brida D, Tomadin A, Manzoni C et al (2013) Ultrafast collinear scattering and carrier multiplication in graphene. Nat Commun 4:1987
145. Zhang TF, Chang HC, Wu YP et al (2015) Macroscopic and direct light propulsion of bulk graphene material. Nat Photon 9(7):471-476

146. Lu YH, Yang Y, Zhang TF et al (2016) Photoprompted hot electrons from bulk cross-linked graphene materials and their efficient catalysis for atmospheric ammonia synthesis. ACS Nano 10(11):10507-10515

147. Yang Y, Zhang TF, Ge Z et al (2017) Highly enhanced stability and efficiency for atmospheric ammonia photocatalysis by hot electrons from a graphene composite catalyst with $\mathrm{Al}_{2} \mathrm{O}_{3}$. Carbon 124:72-78

148. Zhao YF, Zhao YX, Waterhouse GIN et al (2017) Layered-double-hydroxide nanosheets as efficient visible-light-driven photocatalysts for dinitrogen fixation. Adv Mater 29(42):1703828

149. Wang SY, Hai X, Ding $X$ et al (2017) Light-switchable oxygen vacancies in ultrafine $\mathrm{Bi}_{5} \mathrm{O}_{7} \mathrm{Br}$ nanotubes for boosting solar-driven nitrogen fixation in pure water. Adv Mater 29(31): 1701774

150. Sun SM, An Q, Wang WZ et al (2017) Efficient photocatalytic reduction of dinitrogen to ammonia on bismuth monoxide quantum dots. J Mater Chem A 5(1):201-209

151. Banerjee A, Yuhas BD, Margulies EA et al (2015) Photochemical nitrogen conversion to ammonia in ambient conditions with FeMoS-chalcogels. J Am Chem Soc 137(5):2030-2034

152. Liu J, Kelley MS, Wu WQ et al (2016) Nitrogenase-mimic ironcontaining chalcogels for photochemical reduction of dinitrogen to ammonia. Proc Natl Acad Sci 113(20):5530-5535

153. Walter MG, Warren EL, McKone JR et al (2010) Solar water splitting cells. Chem Rev 110(11):6446-6473

154. Li CC, Luo ZB, Wang T et al (2018) Surface, bulk, and interface: rational design of hematite architecture toward efficient photoelectrochemical water splitting. Adv Mater 30(30):1707502

155. Chang XX, Wang T, Gong JL (2016) $\mathrm{CO}_{2}$ photo-reduction: insights into $\mathrm{CO}_{2}$ activation and reaction on surfaces of photocatalysts. Energy Environ Sci 9(7):2177-2196

156. Dickson CR, Nozik AJ (1978) Nitrogen fixation via photoenhanced reduction on p-gallium phosphide electrodes. J Am Chem Soc 100(25):8007-8009

157. Zhu D, Zhang LH, Ruther RE et al (2013) Photo-illuminated diamond as a solid-state source of solvated electrons in water for nitrogen reduction. Nature Mater 12(9):836-841

158. Oshikiri T, Ueno K, Misawa H (2014) Plasmon-induced ammonia synthesis through nitrogen photofixation with visible light irradiation. Angew Chem Int Ed 53(37):9802-9805

159. Ali M, Zhou FL, Chen K et al (2016) Nanostructured photoelectrochemical solar cell for nitrogen reduction using plasmonenhanced black silicon. Nat Commun 7:11335

160. Oshikiri T, Ueno K, Misawa H (2016) Selective dinitrogen conversion to ammonia using water and visible light through plasmon-induced charge separation. Angew Chem Int Ed 55(12):3942-3946

161. Li L, Wang YC, Vanka S et al (2017) Nitrogen photofixation over III-nitride nanowires assisted by ruthenium clusters of low atomicity. Angew Chem Int Ed 129(30):8827-8831

162. Zheng JY, Lyu YH, Qiao M et al (2019) Photoelectrochemical synthesis of ammonia on the aerophilic-hydrophilic heterostructure with $37.8 \%$ efficiency. Chemistry 5(3):617-633

163. Weng B, Qi MY, Han C et al (2019) Photocorrosion inhibition of semiconductor-based photocatalysts: basic principle, current development, and future perspective. ACS Catal 9(5):4642-4687

164. Jiao F, Xu BJ (2019) Electrochemical ammonia synthesis and ammonia fuel cells. Adv Mater 31(31):1805173

165. Hong J, Pancheshnyi S, Tam E et al (2017) Kinetic modelling of $\mathrm{NH}_{3}$ production in $\mathrm{N}_{2}-\mathrm{H}_{2}$ non-equilibrium atmospheric-pressure plasma catalysis. J Phys D Appl Phys 50(15):154005 
166. Eliasson B, Kogelschatz U (1991) Modeling and applications of silent discharge plasmas. IEEE Trans Plasma Sci 19(2):309-323

167. Carrasco E, Jiménez-Redondo M, Tanarro I et al (2011) Neutral and ion chemistry in low pressure dc plasmas of $\mathrm{H}_{2} / \mathrm{N}_{2}$ mixtures: routes for the efficient production of $\mathrm{NH}_{3}$ and $\mathrm{NH}_{4}^{+}$. Phys Chem Chem Phys 13(43):19561-19572

168. Peng P, Li Y, Cheng Y et al (2016) Atmospheric pressure ammonia synthesis using non-thermal plasma assisted catalysis. Plasma Chem Plasma Process 36(5):1201-1210

169. Aihara K, Akiyama M, Deguchi T et al (2016) Remarkable catalysis of a wool-like copper electrode for $\mathrm{NH}_{3}$ synthesis from $\mathrm{N}_{2}$ and $\mathrm{H}_{2}$ in non-thermal atmospheric plasma. Chem Commun 52(93): 13560-13563

170. Iwamoto M, Akiyama M, Aihara K et al (2017) Ammonia synthesis on wool-like $\mathrm{Au}, \mathrm{Pt}, \mathrm{Pd}, \mathrm{Ag}$, or $\mathrm{Cu}$ electrode catalysts in nonthermal atmospheric-pressure plasma of $\mathrm{N}_{2}$ and $\mathrm{H}_{2}$. ACS Catal 7(10):6924-6929

171. Yandulov DV, Schrock RR (2003) Catalytic reduction of dinitrogen to ammonia at a single molybdenum center. Science 301(5629):76-78

172. Arashiba K, Miyake Y, Nishibayashi Y (2011) A molybdenum complex bearing PNP-type pincer ligands leads to the catalytic reduction of dinitrogen into ammonia. Nat Chem 3(2):120-125

173. Lancaster KM, Roemelt M, Ettenhuber P et al (2011) X-ray emission spectroscopy evidences a central carbon in the nitrogenase iron-molybdenum cofactor. Science 334(6058):974-977

174. Spatzal T, Aksoyoglu M, Zhang L et al (2011) Evidence for interstitial carbon in nitrogenase FeMo cofactor. Science 334(6058):940

175. Rodriguez MM, Bill E, Brennessel WW et al (2011) $\mathrm{N}_{2}$ reduction and hydrogenation to ammonia by a molecular iron-potassium complex. Science 334(6057):780-783

176. Anderson JS, Rittle J, Peters JC (2013) Catalytic conversion of nitrogen to ammonia by an iron model complex. Nature 501(7465):84-87

177. Črić I, Mercado BQ, Bill E et al (2015) Binding of dinitrogen to an iron-sulfur-carbon site. Nature 526(7571):96-99

178. Shima T, Hu SW, Luo G et al (2013) Dinitrogen cleavage and hydrogenation by a trinuclear titanium polyhydride complex. Science 340(6140):1549-1552

179. Falcone M, Chatelain L, Scopelliti R et al (2017) Nitrogen reduction and functionalization by a multimetallic uranium nitride complex. Nature 547(7663):332-335

180. Falcone M, Barluzzi L, Andrez J et al (2019) The role of bridging ligands in dinitrogen reduction and functionalization by uranium multimetallic complexes. Nat Chem 11(2):154-160

181. Foster SL, Bakovic SIP, Duda RD et al (2018) Catalysts for nitrogen reduction to ammonia. Nat Catal 1(7):490-500
182. Comer BM, Liu YH, Dixit MB et al (2018) The role of adventitious carbon in photo-catalytic nitrogen fixation by titania. J Am Chem Soc 140(45):15157-15160

183. An Q, Shen YD, Fortunelli A et al (2018) QM-mechanism-based hierarchical high-throughput in silico screening catalyst design for ammonia synthesis. J Am Chem Soc 140(50):17702-17710

184. Huang PC, Liu W, He ZH et al (2018) Single atom accelerates ammonia photosynthesis. Sci China Chem 61(9):1187-1196

185. Zhao JX, Chen ZF (2017) Single Mo atom supported on defective boron nitride monolayer as an efficient electrocatalyst for nitrogen fixation: a computational study. J Am Chem Soc 139(36):12480-12487

186. Liu X, Jiao Y, Zheng Y et al (2019) Building up a picture of the electrocatalytic nitrogen reduction activity of transition metal single-atom catalysts. J Am Chem Soc 141(24):9664-9672

187. Milton RD, Abdellaoui S, Khadka N et al (2016) Nitrogenase bioelectrocatalysis: heterogeneous ammonia and hydrogen production by MoFe protein. Energy Environ Sci 9(8):2550-2554

188. Michalsky R, Avram AM, Peterson BA et al (2015) Chemical looping of metal nitride catalysts: low-pressure ammonia synthesis for energy storage. Chem Sci 6(7):3965-3974

189. Gao WB, Guo JP, Wang PK et al (2018) Production of ammonia via a chemical looping process based on metal imides as nitrogen carriers. Nat Energy 3(12):1067-1075

190. Medford AJ, Vojvodic A, Hummelshøj JS et al (2015) From the Sabatier principle to a predictive theory of transition-metal heterogeneous catalysis. J Catal 328:36-42

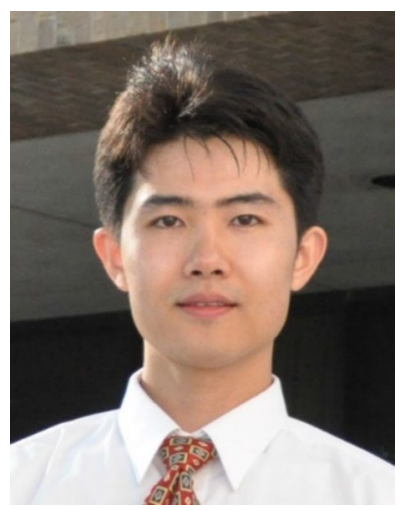

TuoWang received his BS degree from Tianjin University and his $\mathrm{PhD}$ degree from the University of Texas at Austin, both in chemical engineering. After gaining another year of research experience as a postdoctoral associate, he joined Lam Research Corp. as a PECVD process development engineer in Tualatin, Oregon. He joined the faculty of the School of Chemical Engineering at Tianjin University, where he is currently a full professor. His research focuses on photoelectrochemical water splitting, $\mathrm{CO}_{2}$ reduction and $\mathrm{NH}_{3}$ reduction based on semiconductor thin films. 